\title{
Lithium Plating Detection Methods in Li-ion Batteries
}

\author{
U. Janakiraman ${ }^{\mathrm{a}}$, Taylor R. Garrick ${ }^{\mathrm{b}}$ and M.E. Fortier ${ }^{\mathrm{a}}$ \\ a Battery Cell Engineering, General Motors, Warren, MI 48093, USA \\ ${ }^{\mathrm{b}}$ Global Virtual Powertrain \& Electrification, General Motors, Warren, MI 48093, USA
}

Lithium-ion batteries (LiB) offer a low-cost, long cycle-life and high energy density solution to the automotive industry. There is a growing need of fast charging batteries for commercial application. However, under certain conditions of high currents and/or low temperatures, the chance for Li plating increases. If the anode surface potential falls below $0 \mathrm{~V}$ versus $\mathrm{Li} / \mathrm{Li}^{+}$, the formation of metallic $\mathrm{Li}$ is thermodynamically feasible. Therefore, determination of accurate Li plating curve is crucial in estimating the boundary conditions for battery operation without compromising life and safety. There are various electrochemical and analytical methods that are employed in deducing the Li plating boundary of the Li-ion batteries. The present paper reviews the common test methods and analysis that are currently utilized in Li plating determination. Knowledge gaps are identified, and recommendations are made for the future development in the determination and verification of Li plating curve in terms of modeling and analysis.

\section{Introduction}

Li-ion batteries (LiBs) have been widely used in various applications like electric vehicles and energy storage systems, which require great durability and safety. For practical applications, fast charge capability of the battery is desired, such as $15 \mathrm{~min}$ charging to $80 \%$ state of charge (SOC). However, certain charging conditions are known to provoke Li plating which can impact safety. ${ }^{[1-6]} \mathrm{Li}$ plating is an undesired side reaction on the anode side of $\mathrm{Li}$-ion batteries. Li ions are reduced to metallic $\mathrm{Li}$ instead of intercalating into the anode crystal structure. Deposition of metallic Li also enables dendrite formation. This occurs where the local anode potential drops down to $0 \mathrm{~V}$ vs. $\mathrm{Li} / \mathrm{Li}^{+}$. In the presence of local inhomogeneity of the graphite anode surface, Li plating can be localized ${ }^{[7,8]}$. It can also be induced by slow intercalation kinetics and high SEI (Solid Electrolyte Interface) film resistances in the anode, due to low temperatures or high current rates ${ }^{[9,10]}$ as well as by a slow diffusion processes ${ }^{[11,12]}$. A poorly designed cell or wrong charging protocols may also cause Li plating. Anode material type influences $\mathrm{Li}$ plating due to the differences in equilibrium potential; Li titanate is the least affected by $\mathrm{Li}$ plating and hard carbon is better than graphite ${ }^{[10,13]}$. Similarly, electrolyte composition also affects the low-temperature performance of Li-ion batteries ${ }^{[9,14-16]}$. In general, the deposited metallic $\mathrm{Li}$ is reversible. However, during oxidation, Li dendrites can lose contact with the active material, leading to dead $\mathrm{Li}$ in the cell ${ }^{[17]}$. Furthermore, the plated metallic Li is highly reactive and forms and irreversible SEI with the electrolyte ${ }^{[18,19]}$. Both, the dead $\mathrm{Li}$ as well as its SEI, lead to a fast capacity fade of the battery. Therefore, measurement of cell capacity and resistance serve as the direct way to detect Li plating. Different studies suggest that metallic Li deposited on a graphite electrode is partly reversible. It has been reported that deposited $\mathrm{Li}$ can re-intercalate into the graphite during relaxation of the electrode. ${ }^{[11,20]}$ Oxidation ('stripping') of metallic Li was observed during 
discharge processes. Both processes of Li recovery (re-intercalation as well as stripping) can be directly observed in the cell potential. ${ }^{[21-23]}$

Methods for detection of Li plating can be divided into the following categories: (1) Measurement of anode potential vs $\mathrm{Li} / \mathrm{Li}^{+}$with a reference electrode ${ }^{[24-27]}$. (2) Battery destructive physical analysis and imaging of anode. ${ }^{[28,29]}$ (3) Electron Paramagnetic Resonance (EPR) ${ }^{[30,31]}$ and Nuclear Magnetic Resonance (NMR) ${ }^{[32,33]}$ to detect a particular range of resonance frequency corresponding to metallic Li. (4) High precision measurement of coulombic efficiency ${ }^{[34,35]}$ in which the plot of coulombic inefficiency per hour versus time fall on the same curve for different tests if cell aging is dominated by SEI growth. Deviation from this curve indicates Li plating. (5) Measurement of cell thickness ${ }^{[36-39]}$. Li metal deposition induces larger volume change than $\mathrm{Li}^{+}$intercalation into graphite, estimated to be $0.37 \mathrm{~cm}^{3} / \mathrm{Ah}^{[36]}$. Thickness change becomes irreversible when Li plating occurs. (6) Measurement of graphite lithiation degree via in-situ Neutron Diffraction ${ }^{[40]}$. (7) Detection of a distinct voltage plateau after charging ${ }^{[9,21-23,41-44]}$. In addition to the above techniques, there are several new methods evolved in the recent years such as (8) AC impedance analysis ${ }^{[45]}$ in which the plot of interfacial impedance versus SOC decreases with increasing SOC when Li plating occurs (9) Accelerated Rate Calorimetry ${ }^{[46]}$ which measures the heat of reaction in the presence of plated Li (10) Acoustic Time of Flight ${ }^{[47]}$ detection of transmitted ultrasonic waves as it changes with cell thickness during Li plating and (11) Mass Spectrometry Titration ${ }^{[48]}$ to quantify the SEI components. The details of these different methods will be discussed in this review article.

The most common Li plating detection method is the detection of voltage plateau due to Li stripping process which thereby indicates the occurrence of Li plating during charging. The voltage plateau can occur either at the beginning of discharge or of relaxation after charging. Among the above methods, voltage plateau is the most feasible method for online detection of Li plating in real-world applications, as it is nondestructive and does not require special and expensive equipment. Prior works demonstrated the feasibility of adopting voltage plateau as a method for Li plating detection. Therefore, mathematical models have been extensively applied to predict performance and life of LiBs and gain fundamental insights into the internal cell characteristics. ${ }^{[49-56]}$ Several works have been reported to study Li plating during overcharge ${ }^{[57,58]}$ or during charge at high rates and/or low temperatures ${ }^{[33,59]}$, and to study the capacity loss induced by Li plating ${ }^{[60]}$. Most of these models only considered Li plating process and neglected Li stripping process; thus, cannot capture the voltage plateau behavior. Hein and Latz ${ }^{[61-64]}$ attempted to simulate $\mathrm{Li}$ stripping and the associated voltage plateau behavior, using a 3D microscopic model. It is shown that Li metal distribution is highly nonuniform in the anode.

In this review, we are offering an overview of the various Li plating detection and analysis methods, including mathematical models that are used for simulating the electrochemical characterization of the Li plating event. 


\section{Discussion}

\section{Three Electrode Diagnostics}

During charging at low temperatures, high rates, and high states of charge, the deposition of metallic Li on anodes occurs which leads to rapid battery aging and failure. ${ }^{[11}$, 19, 21, 34, 65-69] This Li deposition on anodes can be detected in battery cells with a reference electrode. ${ }^{[19,65,68,70]}$ However, commercial cells in automotive or consumer electronics applications do not contain a reference electrode. Recently, much work has been done using a three-electrode setup (i.e. anode, cathode, and reference.) ${ }^{[68,70-72]}$

Bhardwaj ${ }^{[70]}$ used a Li reference electrode built into a cell to investigate a charging strategy to avoid Li deposition on anodes. Zhang ${ }^{[68]}$ utilized a reference electrode while investigating a stepwise charging procedure with reduced current at the beginning of charging followed by a higher current. Itou ${ }^{[71]}$ collected electrodes from aged cells and reconstructed them together with a Li reference electrode and were able to determine the resistances of the anode and the cathode versus the reference separately. Waldmann ${ }^{[73]}$ constructed three-electrode cells from commercial 18650s with the addition of a $\mathrm{Li}$ reference electrode. This allowed for the measurement of the anode potential against the Li reference during charging of the reconstructed cells and determination of Li deposition. Waldmann observed from anode potential measurement that Li deposition on anodes in commercial cells is possible even at ambient temperature and low charge rates.

Koch $^{[74]}$ has also done work on three electrode setups. These offer the ability to monitor the onset of Li plating in an electric vehicle and link with controller logic in a battery management system. However, to date, this type of reference electrode setup has not been seen in a vehicle application. Commercial cells in automotive or consumer electronics applications do not contain a reference electrode. Moreover, the location of a reference electrode should be carefully controlled to measure resistances at each electrode and solid-state diffusion rates.

\section{Measurement of Coulombic Efficiency}

There are two kinds of Li plating, reversible and irreversible. Reversible Li plating describes deposited $\mathrm{Li}$ that is in electrical contact with the negative electrode. Therefore, reversibly plated $\mathrm{Li}$ is stripped during the discharge step, i.e.

$Q_{\text {stripping }}=Q_{\text {rev,plating }}$

This reversible part does not cause any capacity loss because it is just another way of charging the graphite electrode. In contrast, irreversibly plated Li exhibits only fragile electrical contact with the negative electrode. Such Li may become electrically isolated from the graphite electrode during the stripping process. Irreversible plating, i.e. dead Li, is thus mainly responsible for the capacity losses during low temperature charging with high currents. ${ }^{[21]}$ 
There are additional capacity losses due to the formation of surface films on the plated Li. At first, Li is plated directly on the electrode surface. ${ }^{[75]}$ The plated Li can grow through the SEI and react with the electrolyte. ${ }^{[11]}$ Subsequent surface film formation causes capacity losses which are not distinguishable from irreversible plating. Moreover, the formation of such surface films can also cause electrical isolation of deposited Li. ${ }^{[59]}$ The charge corresponding to irreversible plating $Q_{\text {rev,plating }}$ includes the capacity loss caused by surface film formation. It is generally assumed that capacity losses due to SEI formation are negligible at low temperatures. The capacity loss during a charge/discharge cycle is simply the difference between the charge throughput during charge $\mathrm{Q}_{\mathrm{ch}}$ and discharge $\mathrm{Q}_{\mathrm{dc}}$, i.e. $\mathrm{Q}_{\text {irrev.plating }}=\mathrm{Q}_{\mathrm{ch}}-\mathrm{Q}_{\mathrm{dc}}$. The total charge during $\mathrm{Li}$ plating is $\mathrm{Q}_{\text {plating }}=\mathrm{Q}_{\text {rev.plating }}+$ Qirrev.plating. The reversibility " $R$ " of the plating process, $R=Q_{\text {rev.plating }} / Q_{\text {plating. }}$. The amount of Li plating, $\mathrm{n}_{\text {plating }}=\mathrm{Q}_{\text {plating }} / \mathrm{F}\left(\text { Faraday constant } \mathrm{F}=96485.3399 \mathrm{C} \mathrm{mol}^{-1}\right)^{[76]}$ as Li plating is a one-electron process $\left(\mathrm{Li}^{+}+\mathrm{e}^{-} \rightarrow \mathrm{Li}\right)$. The mass of plated $\mathrm{Li}$ mplating is then calculated according to $\mathrm{m}_{\text {plating }}=\mathrm{n}_{\text {plating }} \mathrm{M}_{\mathrm{Li}}\left(\right.$ molar mass of $\left.\mathrm{Li} \mathrm{M} \mathrm{Mi}_{\mathrm{Li}}=6.94 \mathrm{~g} \mathrm{~mol}^{-1}\right){ }^{\left[{ }^{[76}\right]}$

Reversibility " $R$ " of the plating process can be determined by the quantitative detection method. The reversibility shows maxima at medium SOC and decreases towards high SOC. At high SOC, the following processes can take place: formation of fragile Li deposit, subsequent chemical intercalation of some of the plated $\mathrm{Li}$, and surface film formation on the residual plated Li. These processes lead to poor electrical pathway and eventual isolation of fragile Li deposit during Li stripping. Such dead Li cannot be stripped and is therefore electrochemically inactive, i.e. the reversibility is reduced. At low SOC, an unknown degradation mechanism leads to capacity losses in addition to Li plating. At a given SOC, reversibility is reduced with decreasing temperature. Li plating increases at lower temperatures due to kinetic polarization effects. Thus, more plated $\mathrm{Li}$ is prone to lose its electrical contact with the graphite electrode, which aggravates irreversible plating and reduces the reversibility. The coulombic efficiency $\mathrm{CE}$ describes the ratio between discharge and charge during one cycle, i.e. $C E=Q_{d c} / Q_{c h}$. It typically illustrates capacity losses during charging, e.g. SEI formation at ambient temperatures. $\mathrm{CE}$ at low temperatures can be understood by the following equation, $\mathrm{CE}=\left(\mathrm{Q}_{\mathrm{ch}}-\mathrm{Q}_{\text {irrev.plating }}\right) / \mathrm{Q}_{\mathrm{ch}}$. Thus, the coulombic efficiency exhibits a contrary SOC dependence compared to irreversible plating for constant temperature. In a plot of SOC vs CE, a linear SOC dependence of the plated Li mass is observed for low to medium SOC values. Decreasing temperature leads to higher Li plating growth rates and shifts the plating initiation point to lower SOC which means that the plating process starts earlier. Both results are attributed to increased kinetic effects. This method is suitable for all cathode materials without a pronounced voltage plateaus in the discharge profile. It is crucial that the stripping plateau is clearly identifiable and not overlain by plateaus of the cathode material.

\section{$\underline{\text { High Precision Coulometry }}$}

As we saw in the previous section, when Li plating occurs during cycling, the coulombic efficiency of the cell will decrease. Based on this premise, Li plating should be detectable as small changes to the coulombic efficiency of cells cycling at different rates. This implies that the detection limits for Li plating will be dictated by the precision and accuracy of measurements of the coulombic efficiency. A High Precision Charger ${ }^{[34,77]}$ should therefore have a high degree of sensitivity for detecting Li plating in any cell type under standard cycling conditions. Burns et al carried out the High Precision Coulometry 
(HPC) study on a 3.4 Ah Panasonic 18650 (NCA/graphite) cells at different charge rates. They cycled the cells at $25^{\circ} \mathrm{C}$ and between 2.8 and $4.2 \mathrm{~V}$ at charge rates of $\mathrm{C} / 10, \mathrm{C} / 5, \mathrm{C} / 3$, $\mathrm{C} / 2$ or $1 \mathrm{C}$ and a discharge rate of $\mathrm{C} / 10$ on the High Precision Charger. A class " $\mathrm{A}$ " resistance temperature detector (RTD) (US Sensor, PPG101A1) was attached to the cells to measure variations in cell temperature at high rates. After cycling, cells were discharged to $0 \mathrm{~V}$ (to ensure safety while opening) and opened to look for evidence of Li plating on the negative electrode. The coulombic efficiency (CE) was time normalized to compare cells that are in the time (h) dependent regime. The coulombic inefficiency normalized over time $(\mathrm{CIE} / \mathrm{h})$ shows all cells at low rates fall on the same curve indicating, they are in a purely time dependent degradation regime which agrees well with the previous work from Smith et al. ${ }^{[78,79]}$ However, when charging at $1 \mathrm{C}$ or higher the $\mathrm{CIE} / \mathrm{h}$ becomes worse than those cells in the time dependent regime indicating the occurrence of Li plating. Based on the work of Smith et al. ${ }^{[78,79]}$ it was shown that normally parasitic reactions are predominantly time dependent and cycle independent. The only exception is parasitic reactions on Silicon negative electrodes which are expected to be strongly cycle dependent due to the large volume changes during each cycle. Therefore, the increase in CIE/h must be attributed to Li plating as it is a cycle dependent degradation mode. As can be seen in Figure 1, with increasing rate, the amount of Li plating/stripping increases, and the CIE/h gets worse.

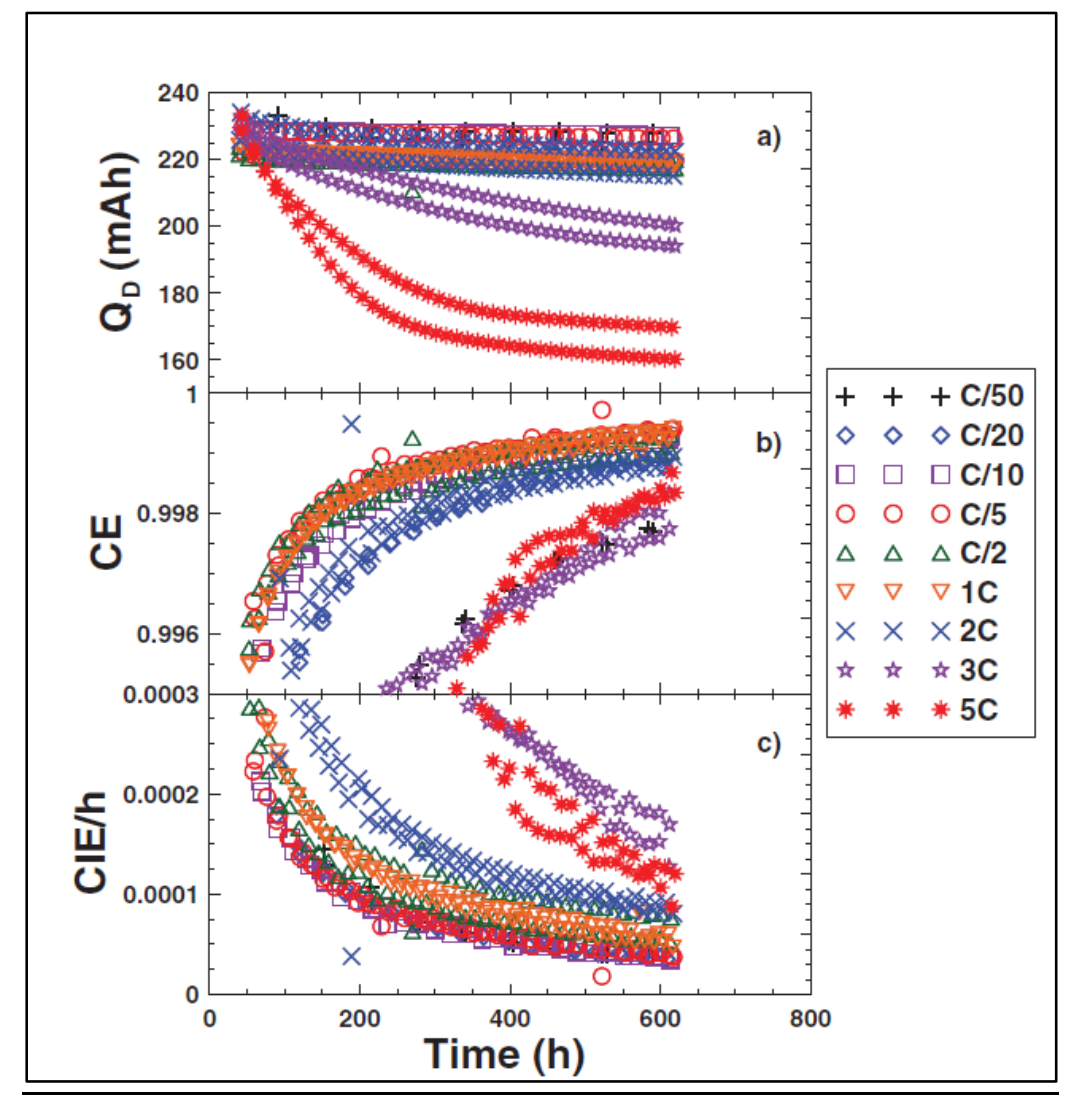

Figure 1. Capacity and Coulombic efficiency and inefficiency per hour (CIE/h) versus time for pouch cells cycling at $30^{\circ} \mathrm{C}$ during cycling with a two-step charge process from $\mathrm{C} / 50$ to $5 \mathrm{C}$ charge rates. Reprinted from J. C. Burns et al, Journal of The Electrochemical Society, 162 (6) A959-A964 (2015). ${ }^{[34]}$ (CC BY, https://creativecommons.org/licenses/by/4.0). 
From this data it can be seen when Li plating occurs it causes an increase in the degradation rate of the cells. The cells charged at a $5 \mathrm{C}$ rate lessen their capacity loss rate around 200 hours (near $170 \mathrm{mAh}$ of remaining capacity) which is likely due to the large difference in over potential of the negative electrode relative to the positive electrode. When the cell is reaching the upper cutoff potential of $4.2 \mathrm{~V}$, the state of charge of the graphite is significantly less than in the early cycles (hence the lower full cell capacity). As graphite is not being charged to as high an electrode state of charge, the voltage curve of the graphite no longer reaches $0 \mathrm{~V}$ vs $\mathrm{Li} / \mathrm{Li}^{+}$to initiate $\mathrm{Li}$ plating even with the same overpotential from the high current.

Figure 2 shows the results for $\mathrm{CIE} / \mathrm{h}$ as a function of charge rate at different temperatures. Coulombic efficiency and CIE/h are taken as an average over the final $\sim 50$ hours of cycling while fade is taken as a linear fit to the capacity versus time data over that same final $\sim 50$ hours. Figure 2 shows that the CIE/h for cells cycled at lower rates at a given temperature is a constant. At lower temperature this constant is smaller as the degradation rate is less (than at higher temperature) due to the slower rate of parasitic reactions. However, as the rate is increased, the CIE/h begins to deviate from the low-rate constant value and becomes larger (worse). This leads to "kinks" in the CIE/h versus rate curves where $\mathrm{CIE} / \mathrm{h}$ is constant during the time dependent regime and then increases with rate during the charge rate dependent regime (where Li plating occurs). The "kinks" indicate the charge rate at which Li plating begins at that temperature. There are measurable differences in the fade rates (especially when the efficiency becomes very poor at high rates) but the difference in fade rates is so small that it is much easier to resolve the onset of plating by examining the CIE/h. They confirmed Li plating in their study, by opening the cells after cycling at different rates at $\sim 50 \%$ state of charge and inspecting the anodes, in an argon-filled glove box.

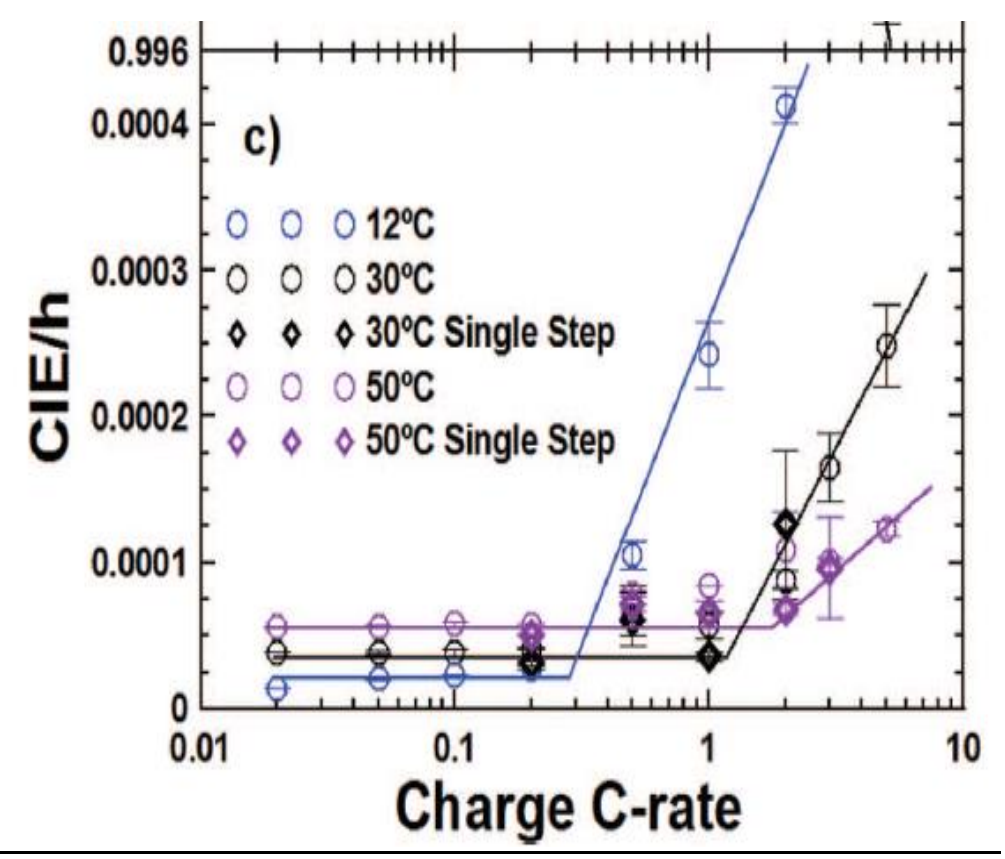

Figure 2. Charge $\mathrm{C}$-rate vs $\mathrm{CIE} / \mathrm{h}$ to $5 \mathrm{C}$ charge rates at different temperatures. Reprinted from J. C. Burns et al, Journal of The Electrochemical Society, 162 (6) A959-A964 (2015). ${ }^{[34]}$ (CC BY, https://creativecommons.org/licenses/by/4.0) 
Figure 2 shows a clear indication of the Li plating as opposed to the Li deposition/stripping curve from the $\mathrm{dV} / \mathrm{dt}$ or $\mathrm{dV} / \mathrm{dQ}$ plots. At $12^{\circ} \mathrm{C}$, the "kink" in the $\mathrm{CIE} / \mathrm{h}$ curve occurs between $\mathrm{C} / 5$ and $\mathrm{C} / 2$ which implies that the cell charged at $\mathrm{C} / 5$ should not show Li plating while the cell charged at $\mathrm{C} / 2$ should show small amounts and then the higher. Thus, high precision coulometry when coupled with a robust thermal chamber is an effective and nondestructive tool for Li plating determination.

\section{Voltage Relaxation and dV/dt}

In the plot of cell voltage against time, the occurrence of voltage plateau is ascribed to stripping of deposited $\mathrm{Li}$ metal and thus indicates that $\mathrm{Li}$ is plated during charging. The voltage plateau can occur either at the beginning of discharge or of relaxation after charging. Among the various methods, voltage plateau is the most feasible method for online detection of Li plating in real-world applications, as it is nondestructive and does not require special and expensive equipment. Smart et al. ${ }^{[9,41]}$ were among the first to apply discharge voltage plateau after low temperature $\left(-40^{\circ} \mathrm{C}\right)$ charging as a tool for Li plating detection and proposed that the length of plateau can be used as a measure of deposited $\mathrm{Li}$ metal amount. Petzl and Danzer ${ }^{[21]}$ presented a differential voltage approach to detect and quantify Li plating. In their tests, a cell was charged with $1 \mathrm{C}$ rate at $<-20{ }^{\circ} \mathrm{C}$ and discharged immediately after charging. A voltage plateau appeared at the beginning of discharge. Later, Uhmann et $a l .{ }^{[22]}$ proposed to detect voltage plateau during relaxation (rest time after charging) rather than during discharge, which is advantageous as the cell has no net current at open-circuit, making the plateau more pronounced and easier to detect. The advantage of analyzing $\mathrm{dV} / \mathrm{dt}$ during post charge relaxation is that data could be easily collected immediately after charging, or by turning off a fraction of the vehicle LiB packs during the first few minutes of driving. In their work by Uhlmann et al ${ }^{[22]}$ the Open Circuit Voltage (OCV) after charge showed plated Li can chemically intercalate into graphite when the cell is at rest. The process of $\mathrm{Li}$ plating followed by intercalation into graphite gives rise to a characteristic 'dual plateau' OCV feature, which is highlighted in Figure 3. ${ }^{[8]}$ This plateau was interpreted as mixed potential resulting from the interplay of $\mathrm{Li}$ intercalation and dissolution of deposited metallic Li on the anode surface. The first potential plateau during relaxation corresponds to the mixed potential of the plated $\mathrm{Li}$ and lithiated graphite $\left(\mathrm{Li}_{\mathrm{x}} \mathrm{C}_{6}\right)$. As the plated $\mathrm{Li}$ chemically intercalates, the mixed $\mathrm{Li} / \mathrm{Li}_{\mathrm{x}} \mathrm{C}_{6}$ potential transitions to a pure $\mathrm{Li}_{\mathrm{x}} \mathrm{C}_{6}$ potential after a threshold amount of surface $\mathrm{Li}$ has been depleted. This phenomena is more prominent as a voltage derivative (Figure 3, Dotted line), which is first proposed by Schindler et al. ${ }^{[23]}$ While differential OCV $(\mathrm{dV} / \mathrm{dt})$ have been used by many groups to study Li plating, the experimental study was either limited to cold temperatures $\left(\leq 0^{\circ} \mathrm{C}\right)$ or charging to high graphite states of charge (SOC). ${ }^{[22]}$ However, EV battery control systems require a technique that indicates initiation of Li plating at high charge rates (C-rates) and at moderate temperatures typically used for fast charge. 


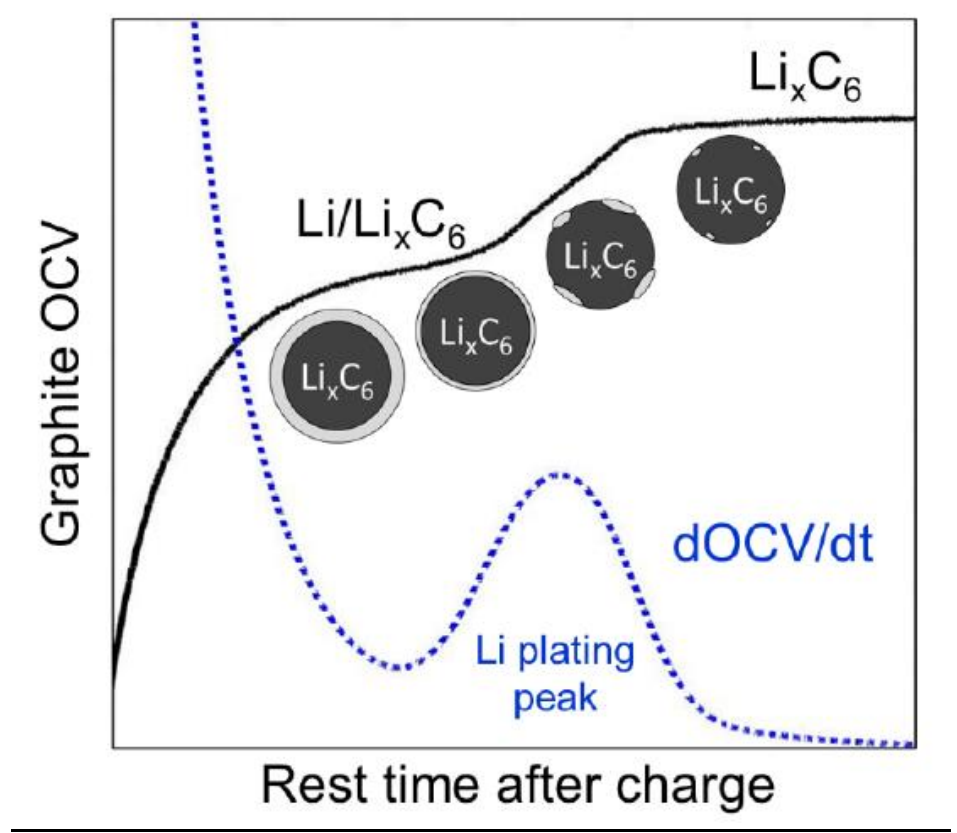

Figure 3: Graphite voltage relaxation after significant Li plating. Reproduced with permission from K. Zachary M., M. Eric J. and M. Bryan D., ACS Energy Lett. 5, 17501757 (2020). ${ }^{[82]}$ Copyright (C) 2020 from American Chemical Society.

The voltage relaxation method was adopted by many other researchers. ${ }^{[23,42,43]}$. Bauer et al. ${ }^{[42]}$ applied this method to study the impacts of charging temperature on Li plating and found that the duration of voltage plateau was longer at lower charging temperatures. This work is closer to real-world applications as the tested cell is a commercial large-size $(16 \mathrm{Ah})$ cell and at practical temperatures $\left(-7.5{ }^{\circ} \mathrm{C} \sim+27.5{ }^{\circ} \mathrm{C}\right)$. Luders et $a l .{ }^{[43]}$ further applied the voltage relaxation method along with in-situ neutron diffraction to examine the impacts of charge rate on Li plating, with a $1.95 \mathrm{Ah} 18650$ cell charged at $-2{ }^{\circ} \mathrm{C}$. The increase of Li plating amount during cell relaxation was estimated from the gain in graphite lithiation degree measured by neutron diffraction and it was found to be proportional to the duration of voltage relaxation plateau. These results indicate that the time to reach $\mathrm{dV} / \mathrm{dt}$ peak can be used for assessing the Li plating amount in different tests. The rate of Li stripping is affected by the capability of $\mathrm{Li}^{+}$intercalation into graphite and by the rate of $\mathrm{Li}^{+}$diffusion and migration from the separator to the foil.

In addition to voltage relaxation $(\mathrm{dV} / \mathrm{dt})$, another widely reported technique for electrochemical Li detection is differential voltage analysis of the discharge profile $(\mathrm{dV} / \mathrm{dQ}$ or $\mathrm{dQ} / \mathrm{dV})$. In the plot of derivative of voltage over capacity (dV/dQ), a distinct peak appeared at the beginning of discharge. This peak indicates the end of Li metal stripping, and the discharge capacity at the $\mathrm{dV} / \mathrm{dQ}$ peak corresponds to the total amount of Li plated during charging. This method can estimate the amount of plated Li based on the length of the plateau. ${ }^{[21,23]}$ While $\mathrm{dV} / \mathrm{dt}$ method require a rest period after charge, $\mathrm{dV} / \mathrm{dQ}$ must have immediate discharge to maximize the signal corresponding to Li stripping. The former is easier to implement whereas the latter can give false positive plating signals ${ }^{[81]}$. Considering the above challenges, $\mathrm{dV} / \mathrm{dt}$ method is found to be the more commercially feasible technology. However, all the electrochemical methods discussed here have 
limitation to detect localized deposition due to averaging effects, which will be discussed later in this article.

\section{$\underline{\text { Li Plating Modeling }}$}

Due to the detrimental effects that Li plating can have on battery performance, a push to develop mathematical methods to predict the onset of metallic Li growth has been seen in recent years. These numerical approaches through modeling offer a way to quantify the amount of plated Li which may offer a clearer picture into the extent of Li plating compared to the experimental in-situ and ex-situ methodologies, and offer the ability to be loaded into controllers ${ }^{[82,83]}$ to provide an electrochemical model for in-vehicle applications. Arora and White may have been the first to propose a set of equations that describe the Li deposition reaction at overcharge. ${ }^{[57]}$ These equations were coupled with traditional porous electrode theory as detailed by Newman and colleagues. ${ }^{\text {[4-91] }}$

Regarding Li transport in a Li ion battery, $\mathrm{Li}$ is assumed to transport from the solid matrix of one active material (such as the anode) governed by transport properties of the active material and reacts at the interface between the active material and the electrolyte governed by the electrochemical kinetics. Li salt in the electrolyte diffuses from one porous electrode, through a separator, to another porous electrode, governed by the liquid phase transport of the electrolyte. At the interface of the second electrode (such as the cathode) and the electrolyte, the Li reacts and intercalates into the solid phase. Traditional porous electrode theory governs these reaction and transport phenomena as is briefly detailed below.

It is assumed that Ohm's law holds in the solid phase of a porous electrode

$i_{1}=-\sigma_{e f f} \frac{d \phi_{1}}{d x}$

with boundary conditions such that charge is maintained and current flows from one porous electrode to another. When considering an electrochemical cell in one dimension, at the interface of one porous electrode and current collector:

$\sigma_{1} \frac{d \phi_{1}}{d x}=i_{a p p}$

At the interface of the second porous electrode and current collector:

$\sigma_{1} \frac{d \phi_{1}}{d x}=-i_{a p p}$

Charge is maintained in the solution phase of each porous electrode,

$i_{2}=-\kappa_{e f f} \frac{d \phi_{2}}{d x}+\left(\frac{2 \kappa_{e f f_{2, a} R T}}{F}\right)\left(1+\frac{d \ln f}{d \ln c_{2}}\right)\left(1-t_{+}\right) \frac{d \ln c_{2}}{d x}$

as well as the separator,

$0=-\kappa_{e f f, s} \frac{d \phi_{2}}{d x}+\left(\frac{2 \kappa_{e f f_{2, S} R T}}{F}\right)\left(1+\frac{d \ln f}{d \ln c_{2}}\right)\left(1-t_{+}\right) \frac{d \ln c_{2}}{d x}$

The material balance in the solution phase of a porous electrode is governed by Fick's law: 
$\frac{d \epsilon_{2} c_{2}}{d t}=-\frac{d}{d x}\left(-D_{e f f_{2}} \frac{d c_{2}}{d x}+\frac{i_{2} t_{+}}{F}\right)-\frac{s_{i}}{n F} \frac{d i_{2}}{d x}$

As well as the separator:

$\frac{d \epsilon_{2, s} c_{2}}{d t}=-\frac{d}{d x}\left(-D_{e f f_{2, s}} \frac{d c_{2}}{d x}\right)$

The material balance in the solid phase is calculated in a pseudo second dimension, hence why it is commonly referred to as a P2D model. Spherical particles are typically assumed and the solid phase $\mathrm{Li}$ concentration is modeled in 1D in the radial direction where:

$\frac{d c_{1}}{d t}=\frac{d\left(D_{1} \frac{d c_{1}}{d r}\right)}{d r}$

$\left.\frac{d c_{1, a}}{d r}\right|_{\mathrm{r}=0}=0$

$-\left.D_{1, a} \frac{d c_{1, a}}{d r}\right|_{\mathrm{r}=\mathrm{r}_{\mathrm{p}}}=\frac{s_{i} j_{a}}{n F} \frac{r_{p}}{3 \epsilon_{2, a}}$

Finally, the electrochemical reactions are governed by the Butler-Volmer equation:

$i_{2}=i_{0}\left(\exp \left(\frac{\alpha_{a} F \eta}{R T}\right)-\exp \left(\frac{-\alpha_{c} F \eta}{R T}\right)\right)$

Most treatment of Li plating using an electrochemical model use the set of equations listed above, with various modifications for the plating physics.

Arora and White proposed a set of equations that describe the Li deposition reaction at overcharge. ${ }^{[57]}$ The rate of the Li deposition reaction is charge-transfer-kinetic controlled and can be expressed by a Butler-Volmer expression as follows

$i_{k}=i_{0, k}\left[\exp \left(\frac{\alpha_{a, c} F}{R T} \eta_{s, k}\right)-\exp \left(\frac{-\alpha_{c, k} F}{R T} \eta_{s, k}\right)\right]$

A number of different approximations can be made to simplify the computational processes while including the Li deposition side reaction. The cathodic Tafel expression can be used to describe the rate expression if either the deposition reaction is considered to be irreversible or if the amount of Li deposited is very small and reacts quickly with the solvent. In that case, the rate expression will be

$i_{k}=i_{0, k} \exp \left(\frac{-\alpha_{c, k} F}{R T} \eta_{s, k}\right)$

Alternatively, the surface overpotentials may be sufficiently low so that the reaction can be expressed adequately using the linear approximation

$i_{k}=i_{0, k} \frac{\left(\alpha_{a, k}+\alpha_{c, k}\right) F}{R T} \eta_{s, k}$ 
Arora and White ${ }^{[57]}$ assumed that the Li deposition reaction is semi-reversible in that at least part of the deposited Li can dissolve during discharge. Some of the Li may react with the electrolyte to form insoluble product. In the above equations, $i_{0, k}$ is the exchange current density and $\eta_{s, k}$ is the local value of the surface overpotential defined as

$\eta_{s, k}=\phi_{1}-\phi_{2}-U_{k}-F j_{n, k} R_{f i l m}$

where $U_{k}$ is the open-circuit potential. The potential variables $\phi_{1}$ and $\phi_{2}$ represent the potentials in the solid and solution phases, respectively, and $i_{0, k}, \alpha_{a, k}$, and $\alpha_{c, k}$ are the kinetic parameters. Based on the above equations and assumptions, the following kinetic expressions can be derived

$j_{n, 1}=\frac{i_{0,1}}{F}\left[\left[\exp \left(\frac{\alpha_{a, 1} F}{R T}\left[\phi_{1}-\phi_{2}-U_{k}-F j_{n, k} R_{f i l m}\right]\right)\right]-\left[\exp \left(-\frac{\alpha_{c, 1} F}{R T}\left[\phi_{1}-\phi_{2}-U_{k}-\right.\right.\right.\right.$

$\left.\left.\left.\left.F j_{n, k} R_{f i l m}\right]\right)\right]\right]$

and

$j_{n, 2}=\frac{i_{0,2}}{F}\left[\left[\exp \left(\frac{\alpha_{a, 2} F}{R T}\left[\phi_{1}-\phi_{2}-U_{2}-F j_{n, 2} R_{f i l m}\right]\right)\right]-\left[\exp \left(-\frac{\alpha_{c, 2} F}{R T}\left[\phi_{1}-\phi_{2}-U_{2}-\right.\right.\right.\right.$

$\left.\left.\left.\left.F j_{n, k} R_{f i l m}\right]\right)\right]\right]$

where $j_{n, 1}$ and $j_{n, 2}$ correspond to the rates of $\mathrm{Li}$ intercalation and $\mathrm{Li}$ deposition reactions. The normal component of the current density is related to the pore wall flux by $i_{n}=F j_{n}$. The open circuit potential $U_{2}$ is equal to zero in this work because the potential is measured with respect to a Li metal reference electrode in solution at the same local electrolyte concentration.

The interplay between the $\mathrm{Li}$ insertion reaction and the $\mathrm{Li}$ deposition reaction is governed by each set of kinetic parameters, resulting in the following equations governing the exchange current densities:

$$
\begin{aligned}
& i_{0,1}=F\left(k_{a, 1}\right)^{\alpha_{c, 1}}\left(k_{c, 1}\right)^{\alpha_{a, 1}}\left(c_{1}^{0}-c_{1}\right)^{\alpha_{a, 1}}\left(c_{1}\right)^{\alpha_{c, 1}}\left(c_{2}\right)^{\alpha_{a, 1}} \\
& i_{0,2}=F\left(k_{a, 2}\right)^{\alpha_{c, 2}}\left(k_{c, 2}\right)^{\alpha_{a, 2}}\left(c_{2}\right)^{\alpha_{a, 2}}
\end{aligned}
$$

where $i_{0,1}$ is the exchange current density for the insertion reaction and $i_{0,2}$ is the exchange current density for the $\mathrm{Li}$ deposition reaction. Considering a volumetric change due to $\mathrm{Li}$ deposition at the particle level, the exchange current density for the Li deposition reaction is directly related to the growth rate of a $\mathrm{Li}$ film on the particle surface:

$\frac{\partial \delta_{\text {film }}}{\partial_{t}}=-\frac{i_{n, 2} M}{\rho F}$

where $\delta_{\text {film }}$ is the film thickness composed of solid Li and other products and $M$ and $\rho$ are the molecular weight and density of $\mathrm{Li}$ and products.

Tang ${ }^{[92]}$ observed that $\mathrm{Li}$ deposition occurs preferentially at the edges of the electrodes and that extending the negative electrode past the edge of the positive electrode 
can hamper this method of Li plating. A simplified mathematical model was used to simulate this behavior and probe the conditions under which this deposition occurs. This work is a critical extension of the traditional porous electrode model and considered edge effects in the electrodes. Through this work, it was determined that the extension of the negative electrode beyond the edge of the positive electrode provides the excess capacity at the critical location and prevents the Li plating from occurring. Tang ${ }^{[92]}$ assumed small currents and linearized the Bulter-Volmer expression:

$i_{2}=i_{0} \frac{F}{R T} \eta$

and considered the exchange current density, $i_{0}$, as a function of concentration of $\mathrm{Li}$ in the solid phase and electrolyte:

$i_{0}=F k\left(c_{1}^{0}-c_{1}\right)^{\alpha_{a}}\left(c_{1}\right)^{\alpha_{c}}\left(c_{2}\right)^{\alpha_{a}}$

Although a galvanostatic charge means that the total current applied to the electrode is constant with time, the current density along the electrode is non-uniform. This means that a constraint of the system is an integral boundary and is defined as

$\oint_{\text {electrode }} i_{n} d s=I_{\text {set }} l_{+}$

where $l_{+}$is the length of the positive electrode, and $I_{\text {set }}$ is the average applied current density in amperes per meter squared, determined by diving the theoretical capacity of the positive electrode by the time of charge

$I_{\text {set }}=F \frac{C_{+} \rho_{+} w_{+} \Delta_{y}}{t_{\text {charge }}}$

Other groups ${ }^{[33,93,94]}$ have proposed using two different Butler-Volmer equations to build on the work of Arora ${ }^{[57]}$ and White, many of which assume that the open circuit voltage of the Li plating reaction is zero, even though it is known that $\mathrm{Li}$ deposits prior to 0V vs. a Li reference electrode ${ }^{[95-103]}$.

$\operatorname{Ren}^{[93]}$ and colleagues proposed separate kinetics equations for Li plating and $\mathrm{Li}$ stripping, with the Li stripping reaction having the same kinetics as the Li plating reaction. When the overpotential is less than 0, Li plating will occur governed by Eq. M25

$j_{n, 2}=\frac{i_{0,2}}{F}\left[\exp \left(\frac{\alpha_{a, 2} F \eta_{L i}}{R T}\right)-\exp \left(-\frac{\alpha_{c, 2} F \eta_{L i}}{R T}\right)\right]$

When the overpotential is greater than 0 and some quantity of Li that can be removed is present, Li stripping will occur governed by Eq. [M26]

$j_{n, 3}=\frac{i_{0,2}}{F}\left[\exp \left(\frac{\alpha_{a, 2} F \eta_{L i}}{R T}\right)-\exp \left(-\frac{\alpha_{c, 2} F \eta_{L i}}{R T}\right)\right] \frac{\beta n_{L i, r e v}}{1+\beta n_{L i, r e v}}$

In Eq. M26, $\frac{\beta n_{L i, r e v}}{1+\beta n_{L i, r e v}}$ is a correction term limiting the reaction to the amount of reversible Li. $\beta$ is a large value, set to 1000 in Ref. ${ }^{[93]}$, such that the correction term is equal to 1 
when a significant amount of plated $\mathrm{Li}$ is present, and 0 when $n_{L i, r e v}=0$. In both Eq. M25 and Eq. M26

$i_{0,2}=F k_{2}\left(c_{2}\right)^{\alpha_{a, 2}}$

and $\eta_{L i}$ is consistent with Eq. M15.

More recently, Baker and Verbrugge have developed a Multi-Species, MultiReaction (MSMR) Model ${ }^{[104-108]}$ for porous intercalation electrodes that has been applied to plating and dissolution of $\mathrm{Li}$ in a $\mathrm{Li}$ ion cell ${ }^{[108]}$. In the latter work, a set of equations was derived to describe the overcharge of a Li ion cell. Two critical additions to published models were added to address Li plating. First, the handling of $\mathrm{Li}$ deposition and dissolution electrochemical reactions was addressed. Secondly, the plated Li in system can directly interact with the vacant sites in the anode, which will impact the system response. By including these theoretical developments with the MSMR model, the authors were able to illustrate $\mathrm{Li}$ intercalation and plating within a single particle model. One critical observation regarding the thermodynamics of the Li plating reactions shows that the open circuit voltage of the plating reaction with respect to a $\mathrm{Li}$ reference cannot be zero, as commonly assumed. Rather, it is only zero when the surface coverage of plated Li is large enough for the Li to interact with the electrolyte in the same manner as a bulk metallic $\mathrm{Li}$ electrode. Consequentially, when small surface coverages of Li on the surface of the anode particles exists, the plated Li interacts with the anode active material, resulting the OCV of the plated Li being positive, which the authors detail in Eq. 11 in Ref. ${ }^{[108]}$. This provides an update to the historical assumption of Li deposition at $0 \mathrm{~V}$ vs a $\mathrm{Li}$ reference.

In the Multi-Species, Multi-Reaction (MSMR) Model ${ }^{[104-108]}$ a few parameters can be associated with the physical chemistry of the intercalation material enabling a quantitative fit of the open-circuit potential. In this model, different galleries of intercalated $\mathrm{Li}$ are assumed to be in thermodynamic equilibrium, so that their open circuit potentials are equal to some common equilibrium potential of the intercalation material. For each gallery $j$

$$
\begin{aligned}
& U_{1}=U_{j}^{0}+R T \frac{\omega_{j}}{F} \ln \left(\frac{X_{j}-x_{j}}{x_{j}}\right) \\
& x_{j}=\frac{X_{j}}{1+\exp \left[\frac{\frac{F}{R T}\left(U_{1}-U_{j}^{0}\right)}{\omega_{j}}\right]}, x\left(U_{1}\right)=\sum x_{j} \\
& \frac{d x}{d U_{1}}=-\sum_{j=1}^{n} \frac{F}{R T} \frac{1}{\omega_{j}} \frac{X_{j} \exp \left[\frac{F}{R T}\left(U_{1}-U_{j}^{0}\right) / \omega_{j}\right]}{\left(1+\exp \left[\frac{F}{R T}\left(U_{1}-U_{j}^{0}\right) / \omega_{j}\right]\right)} \\
& i_{s, j}=i_{0, j}\left[e^{\frac{(1-\beta) F}{R T} \eta_{s}}-e^{\left.\frac{-\beta F}{R T} \eta_{s}\right], j_{1}=\sum i_{s, j}}\right. \\
& \eta_{s}=\phi_{1}-\phi_{2}-U_{1}(x) \\
& i_{0, j}=i_{0, j}^{r e f}\left(x_{j}\right)^{\omega_{j} \beta_{j}}\left(X_{j}-x_{j}\right)^{\omega_{j}\left(1-\beta_{j}\right)}\left(\frac{c_{2}}{c_{2}^{0}}\right)^{1-\beta_{j}}
\end{aligned}
$$


where $U_{1}$ is the open circuit voltage of the intercalation reaction, $\omega_{j}$ is a thermodynamic parameter fit to the open circuit voltage, $X_{j}$ is the maximum mole fraction of species $j, x_{j}$ is the mole fraction of $\mathrm{Li}$ in the solid phase, and $\beta_{j}$ is the symmetry factor for the $j$ th intercalation reaction. The kinetics for the intercalation reaction are then governed by Eq. M31, a modification of Eq. M12 using the symmetry factor $\beta_{j}$.

The kinetics of the Li plating reaction are then given by

$j_{2}=i_{0, L i}\left[e^{\frac{\left(1-\beta_{\mathrm{Li}}\right) F}{R T} \eta_{s}}-e^{\frac{-\beta_{\mathrm{Li}} F}{R T} \eta_{s}}\right]$

where

$i_{0, L i}=i_{0, j}^{r e f} a_{L i}^{\beta_{L i}}\left(\frac{c_{2}}{c_{2}^{0}}\right)^{1-\beta_{L i}}$

where $a_{L i}$ is the activity coefficient of $\mathrm{Li}$ and is related to the $\mathrm{Li}$ surface concentration and is defined as

$a_{L i}=1-e^{-\Theta}$

where $\Theta$ corresponds to the ratio of the concentration of surface Li compared to a reference value. Combining Eq. M34 - M36 and replacing $\Theta$ with $U_{2}$, the open circuit voltage of the plating reaction yields a kinetics expression that is a function of potentials, electrolyte concentration, and thermodynamic properties:

$j_{2}=i_{0, L i}^{r e f}\left(\frac{c_{2}}{c_{2}^{0}}\right)^{1-\beta_{L i}}\left[e^{-\frac{F}{R T} U_{2}} e^{\frac{F}{R T}\left(1-\beta_{L i}\right)\left(\phi_{1}-\phi_{2}\right)}-e^{\frac{F}{R T}\left(-\beta_{L i}\right)\left(\phi_{1}-\phi_{2}\right)}\right]$

This treatment removes the need for a correction term as seen in Eq. M36 which must be arbitrarily set.

Electrochemical modeling techniques are all based on a set of highly non-linear equations that describe the transport phenomena and electrochemical physics within the battery. While Thevenin ${ }^{[109-123]}$ models or electrochemical impedance spectroscopy models $^{[124-127]}$ (EIS) are popular for fast predictions for electrical performance, they do not enable the user to couple the Li plating physics necessary for analysis. Retaining aspects of the porous electrode model is necessary for Li plating simulation. In order to speed up solution times, many different approximations have been made to simplify the equations and associated solutions depending on the accuracy and speed necessary in a given application.

The prevailing approach for increasing speed for electrochemical models without sacrificing accuracy is to use various mathematical techniques to speed up the solution time for the partial differential equations, or to convert the partial differential equations into a form that can be integrated faster through the use of numerical solvers. Subramanian ${ }^{[128-}$ ${ }^{132]}$ developed various reduction methods that enabled real-time simulations. White has applied various methods such as orthogonal decomposition ${ }^{[133]}$, state-space reformulation ${ }^{[134,135]}$, reducing the system of partial differential equations to ordinary differential equations ${ }^{[135,136]}$, and applying polynomial representations of the $\mathrm{Li}$ ion 
concentration in the solid phase ${ }^{[137]}$. In recent years, the popularity of these models ${ }^{[138-149]}$ has increased due to their relative speed and accuracy.

Due to the development of fast and accurate reduced order models, the potential exists for real time $\mathrm{Li}$ plating estimation within a micro-controller. Zhao ${ }^{[150]}$ utilized a reduced order model ${ }^{[151-153]}$ to consider $\mathrm{Li}$ plating evolution. In this work, the ion concentration in the electrode was reduced using a polynomial approach, the ion concentration in the electrolyte was reduced using the state-space approach, and the electrochemical kinetics (i.e. Butler Volmer Equation) was linearized. Similar to previous approaches, the overall electrochemical reaction was split between the Li intercalation and Li deposition reactions

$j_{\text {total }}^{L i}=j^{L i}+j_{\text {plating }}^{L i}$

$j_{\text {plating }}^{L i}=a_{s} i_{0, p}\left[\exp \left(\frac{\alpha_{a, p} F \eta_{p}}{R T}\right)-\exp \left(-\frac{\alpha_{c, p} F \eta_{L i}}{R T}\right)\right]$

where $i_{0, p}$ is the exchange current density of the Li deposition reaction and was fit as a function of temperature, $\alpha_{a, p}$ and $\alpha_{c, p}$ are the dimensionless anodic and cathodic charge transfer coefficients and were assumed to be 0.33 and 0.67 respectively, due to the assumption of semi-reversibility with the Li deposition reaction. $\eta_{p}$ was calculated similarly to Eq. M15. The authors calculated the Li plating reaction rate (Figure $3 \mathrm{~d}$ in Ref. $\left.{ }^{[150]}\right)$ and illustrate the increase in plating rate at lower temperatures, consistent with experimental studies. ${ }^{[45,63,93,154-158]}$ Choe has applied this reduced order model to investigate degradation with the intent of mitigating aging and $\mathrm{Li}$ plating due to fast charging. ${ }^{[140,150-152,159-163]}$ This type of approach could be utilized in a battery management system or charge controller to avoid Li plating completely, or to allow for a quantifiable amount of $\mathrm{Li}$ plating that could be electrochemically removed later.

Various research groups have approached integration of a full order model or reduced order model into a micro-controller. Perkins ${ }^{[58]}$ developed a control-oriented cell degradation model by deriving a reduced-order model for the Li plating deposition reaction occurring on overcharge. This work illustrated the differences in accuracy between a fullorder model and the reduced order model, while allowing for a 5000x increase in solver speed, illustrating the theoretical capability of loading a ROM onto a micro-controller.

Florentino $^{[164]}$ extended Perkin's work and explored the use of controllers for managing battery cell performance using reduced order electrochemical models. In this work, model predictive control was utilized as a smart sensor and applied to a balancing architecture. As a smart sensor, the model predictive controller is transparent during the operation of a cell, provided that the cell does not enter into a state that would result in aging or Li plating. Once a condition is detected that would result in the cell being prone to Li plating, the model predictive controller intervenes and ensures that the cell does not enter said state.

Subramanian ${ }^{[129,131,132,165-171]}$ has spent decades focused on modeling methods, and has more recently focused on reformulating $[129,131,132,169]$ models for increased computational efficiency, developing battery management systems ${ }^{[168,171]}$ using physics based reformulated models, and applying nonlinear model predictive control ${ }^{[170,171]}$ to $\mathrm{Li}$ 
ion batteries. Subramanian's work has illustrated the tradeoff between computational complexity and accuracy, the need for reduced order models in production in both the automotive and grid storage space, and has provided ample proof that physics based models are the next step in bridging the gap between scientific understanding of aging phenomena and the tools that are used for controls every day.

Real-Time Estimation of Li-Ion Concentration in Both Electrodes of a Li-Ion Battery Cell

To detect Li plating, the first adopted approach was based on two-electrode models ${ }^{[172]}$ where the Li-ions transport rates in and out of the electrodes were used as indicators of the same. However, the approach doesn't estimate the accurate Li-ion concentration. This limitation was overcome by using the extended model and cascaded observers. ${ }^{[173]}$ Dey et al ${ }^{[175]}$ expressed the insertion and extraction rates of the Li-ions as

$$
E_{P}=\left|\frac{\partial C P_{\text {avg }}}{\partial t}\right|, I_{N}=\left|\frac{\partial C N_{\text {avg }}}{\partial t}\right|
$$

where $E_{P}$ and $I_{N}$ are the Li-ion extraction rate from positive electrode and insertion rate into negative electrode, $C P_{\text {avg }}$ and $C N_{\text {avg }}$ are the volume-averaged Li-ion concentrations in the positive and the negative electrodes, respectively, and given as

$$
\begin{aligned}
& C P_{\text {avg }}=\frac{1}{\frac{4}{3} \pi R^{+3}} \int_{0}^{R+} 4 \pi r^{2} C_{s}^{+}(r, t) d r \\
& C N_{\text {avg }}=\frac{1}{\frac{4}{3} \pi(R)^{-3}} \int_{0}^{R-} 4 \pi^{2} C_{s}^{-}(r, t) d r
\end{aligned}
$$

Li plating is detected when the extraction rate $E_{P}$ exceeds the maximum possible extraction rate $\left(E_{P, \max }\right)$ and $I_{N}$ drops below the minimum possible insertion rate $\left(I_{N, \min }\right)$. Their recommend ways to collect $E_{P}$ and $I_{N}$ data are: (1) Monte Carlo simulation studies on the battery model on varying different operating conditions, different levels of measurement noise, and different levels of modeling uncertainties or (2) experimental studies on a physical battery under different operating conditions ${ }^{[8,43]}$. Then, choose the maximum and minimum of $E_{P}$ and $I_{N}$ as the limits. State and Capacity Estimation were performed for constant current and dynamic discharge conditions. The capacity fade is simulated by adding a side reaction current component into the plant-model.

The simulation scenario used for this case study is $\mathrm{C} / 10$ charging at ambient temperature, $20^{\circ} \mathrm{C}$. To illustrate the Li plating condition in simulation scenario a step like additive $\mathrm{C} / 5$ charging input current component was used to the positive electrode of the plant-model. This additive input current causes a sudden change in current density in the positive electrode, while the current density in the negative electrode is kept constant. This essentially represents a loss in active $\mathrm{Li}$-ions, as the $\mathrm{Li}$-ion extraction rate from the positive electrode would be higher than the insertion rate in the negative electrode. In this case study, the positive electrode current density increases at $\mathrm{t}=600 \mathrm{~s}$. Using this approach, the bulk SOC could be tracked even after the occurrence of the plating.

Dey et all also studied the effect of measurement noise via simulation by using different noise levels in the all three measurements (voltage, temperature, and current). It 
is found that the scheme generates reasonable estimates approximately up to $25 \mathrm{mV}$ voltage measurement noise and 50mA current measurement noise. Above those ranges, the steadystate estimation error goes significantly higher reducing the effectiveness of the scheme. Other than measurement noise, measurement bias was also considered. For voltage and current measurements, the scheme performs satisfactorily up to $5 \mathrm{mV}$ and $12 \mathrm{~mA}$ measurement bias. Beyond these values, the performance of the scheme degrades. Above $0.5{ }^{\circ} \mathrm{C}$ noise level in the temperature measurement, the estimates tend to diverge after a certain point when the signal-to-noise ratio gets smaller. The simulation results are yet to be correlated with the experimental measurement.

\section{Electrochemical Impedance Spectroscopy}

Li-ion battery comprises of a series of multiple processes including Li-ion diffusion in the electrolyte, migration through the SEI layer, charge transfer through the electrode/electrolyte interface, solid-state diffusion in the bulk of active material and electron transfer external to the battery via the current collectors ${ }^{[39,40,174]}$. These processes introduce impedance to the charge flow and cause a voltage drop between the two electrodes. Electrochemical Impedance Spectroscopy (EIS) is an efficient tool to identify these processes since each of them has a different time constant or frequency range of excitation. ${ }^{[36,175]}$

In a recent publication, from Koleti et al studied the impedance analysis on a commercially available 18650 -type Li-ion cells with a rated capacity of $3.1 \mathrm{Ah}^{[175]}$. EIS is shown in Figure 4a. in which the high-frequency region $(761 \mathrm{~Hz})$ is caused by the ionic conduction through the electrolyte and electronic conduction through the current collectors whose impedances are represented by $\mathrm{Z}_{\mathrm{EL}}$ and $\mathrm{Z}_{\Omega}$ respectively. In the mid-frequency region, charge transfer limitations (CTL) are caused by the electrode-electrolyte interfaces, $\mathrm{Z}_{\mathrm{CTL}}$ and the ion migration through the SEI layer, $Z_{\text {SEI }}$. The low-frequency part is usually characterized by a $45^{\circ}$ slope, arising from the solid diffusion limitations (SDL) in the electrodes. Figure $4 b$. shows the equivalent circuit of a Li-ion battery. In figure $4 b$, the impedance due to solid diffusion limitations are referred to as $Z_{\mathrm{SDL}, \mathrm{NE}}$ or $Z_{\mathrm{SDL}, \mathrm{PE}}$, and the corresponding electrode surface potential is represented by $\mathrm{V}_{\mathrm{NE}, \mathrm{S}}$ or $\mathrm{V}_{\mathrm{PE}, \mathrm{S}}$; NE and PE stands for negative and positive electrodes, respectively. Figure $4 \mathrm{c}$ shows the EIS plots of the same cell at different SOC levels. As it can be observed [39, 40, 175, 176], during charge/discharge, impedance in the mid-frequency range varies with SOC. Both $\mathrm{Z}_{\mathrm{CTL}}$ and $\mathrm{Z}_{\mathrm{SEI}}$ contribute to this range. As no significant change in the SEI layer thickness is expected in a single charge/discharge cycle ${ }^{[177,178]}$ the mid-frequency impedance variations can be attributed largely to the $\mathrm{Z}_{\mathrm{CTL}}$. The electrochemical models that describes the CTL through the Butler-Volmer equation ${ }^{[21,155,179,180]}$ also support this rationale. At low and high and high lithiation levels $(0 \%$ and $100 \%), Z_{\mathrm{CTL}}$ is high and reduces as the lithiation level moves towards $50 \%$. Therefore, the impedance changes in the mid-frequency region comes mainly from the $\mathrm{Z}_{\mathrm{CTL}}$ and tracking the battery impedance should indicate the way $\mathrm{Z}_{\mathrm{CTL}}$ is changing while the battery is being charged or discharged. The impedance measured at the transition frequency (referred as $\mathrm{ftr}$ which is marked with "*" in Figure 4c) at which impedance changes to $45^{\circ}$ slope allows quantifying the total impedance from both the high

and the mid-frequency regions. Since the impedance from the high-frequency region is nearly constant (as seen from Figure 4c), tracking the transition frequency impedance (referred as ZTR) allows tracking the impedance from the charge transfer limitations, $Z_{\mathrm{CTL}}$ ). 


$$
Z T R=Z_{\Omega}+Z_{S E I}+Z_{E l}
$$

Where $\mathrm{Z}_{\Omega}=\mathrm{Z}_{\Omega 1}+\mathrm{Z}_{\Omega 2}$ and $\mathrm{Z}_{\mathrm{CTL}}=\mathrm{Z}_{\mathrm{CTL}, \mathrm{NE}}+\mathrm{Z}_{\mathrm{CTL}, \mathrm{PE}}$

Here, $Z_{\Omega 1}$ and $Z_{\Omega 2}$ are Ohmic resistances at the NE and PE respectively; $Z_{C T L, N E}$ and $\mathrm{Z}_{\mathrm{CTL}, P \mathrm{E}}$ are impedance due to charge transfer limitations at negative and positive electrodes, respectively. Figure 4d presents the ZTR profile against the battery SOC where ZTR drops initially as battery SOC raises from $0 \%$ and reaches a near flat level in the midSOC range before rising again as SOC goes further towards $100 \%$.
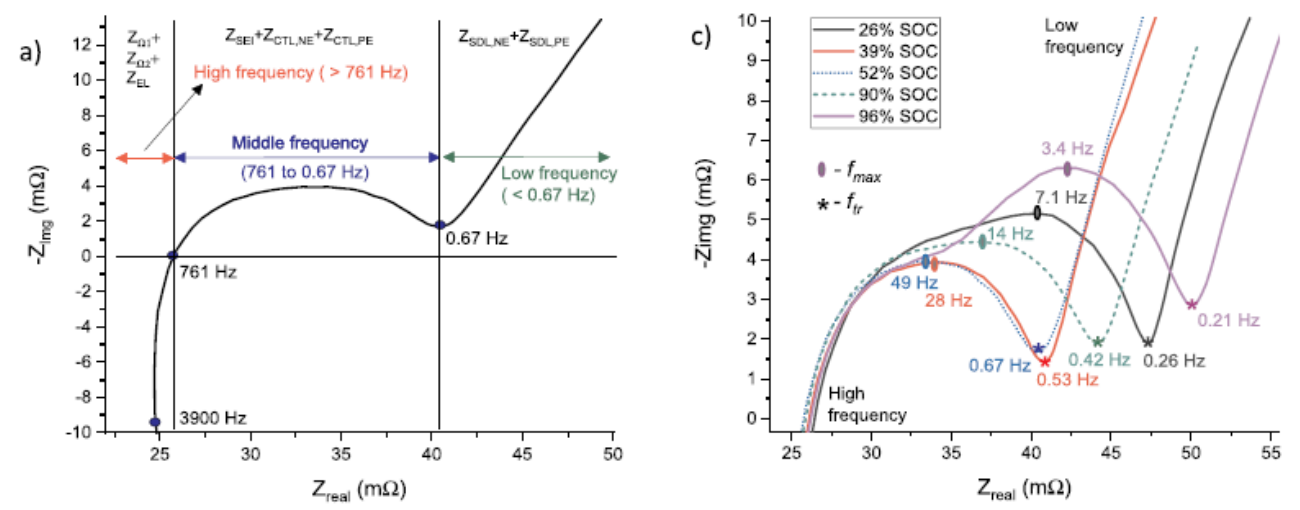

b)

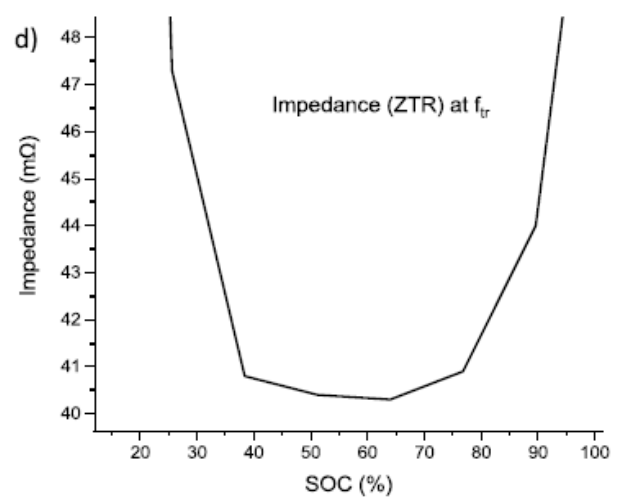

Figure 4: Battery Impedance (a) EIS plot at 50\% SOC (b) Equivalent electrical circuit diagram representation of the battery impedance (c) EIS plots at different SOC levels and (d) Impedance and resistance at the transition frequency, $\mathrm{f}_{\mathrm{tr}}$. Reprinted from U.R. Koleti et al., Journal of Power Sources 451, 227798 (2020). Copyright (2020) with permission from Elsevier.

The method to track the ZTR and thus $\mathrm{Z}_{\mathrm{CTL}}$ while charging/ discharging is similar to the hybrid pulse power characterization (HPPC) test often used in developing equivalent circuit models ${ }^{[181-184]}$. Charge current is interrupted every $1 \%$ SOC increase for a predefined time period. The step-change in the current and the associated voltage change during the interruption is used to calculate the real part of ZTR (referred as RTR) based on Ohms law. As seen from Figure 4c, the imaginary part of the impedance is significantly lower than the resistive part (RTR) irrespective of the SOC level. RTR is found to be within $1 \%$ of the total value of ZTR irrespective of the SOC level. Therefore, variations in ZTR can be tracked using the calculated RTR value. To identify the charge interruption time period, as discussed within Ref. ${ }^{[175]}$ the time constant $(\tau)$ of an equivalent $R C$ network that 
produces the semi-circle in the mid-frequency region can be used. The value of $\tau$ is calculated with the frequency (referred as $f_{\max }$ which is marked with circles in Figure 4c) at which the imaginary part of the impedance attains a maximum level in the mid-frequency region using $\tau=\left(2 \pi f_{\max }\right)^{-1}$. An interruption time of $2 \tau \mathrm{s}$ shall recover the voltage drop due to the RC network by $87 \%$ of the maximum value.

While charging at low C-rates or during high ambient temperatures, differences between the lithiation levels of the electrode surface and the bulk are known to reduce ${ }^{[21-}$ 23, 155, 179] due to the improved diffusion in the electrodes,. Therefore, charging conditions that allow lithiation levels closer to their average can produce a ZTR profile similar to Figure $4 d$ where the lithiation differences in the electrode particles are deemed to be negligible. Conversely, at high C-rates of charging or at low temperatures, the lithiation increase on negative electrode because of reduced solid diffusion. Therefore, at high $\mathrm{C}$ rates $\mathrm{Z}_{\mathrm{CTL}}$ decreases at a lower SOC level compared to charging at low $\mathrm{C}$-rates or high temperatures. With further charging, lithiation tends to increase towards a full lithiation level, as the negative electrode voltage comes closer to Li reference potential much before the battery reaches $100 \%$ SOC. Besides, the potential drop due to charge transfer limitations increases with increasing $\mathrm{C}$-rate or decreasing temperature. The negative electrode potential can fall below the Li reference where Li plating commences. Once Li plating begins, electrode lithiation rise and $\mathrm{Z}_{\mathrm{CTL}}$ decreases since the charging current is now divided into intercalating current and Li plating current. Additionally, as discussed within Ref. ${ }^{[93]}$ and ${ }^{[33]}$, the Li plating reaction at the NE also follows the Butler-Volmer equation that introduces a new branch of impedance in parallel to the existing $\mathrm{Z}_{\mathrm{CTL}, \mathrm{NE}}$. Similar to intercalating current that faces $Z_{\mathrm{CTL}, \mathrm{NE}}$, Li plating current faces an impedance referred here as $Z_{\mathrm{CTL}, \mathrm{Li}}$. As a result, the overall impedance at the NE drops after the onset of Li plating. On this basis, tracking the ZTR will allow detecting the onset of Li plating during the charge event. In the case of a charging event without Li plating, ZTR follows the curve from Figure 4d where it faces continuously decreasing reduction at lower SOC levels to reach a near flat level in the mid-SOC range and then accelerate as SOC rises towards $100 \%$. In the case of a charging event with Li plating, ZTR faces a second downtrend after the onset of Li plating because of the introduction of parallel impedance

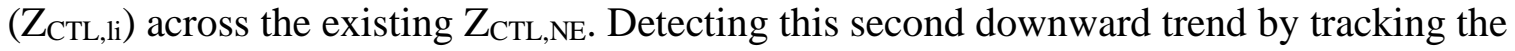
ZTR shall, therefore, indicate the onset of Li plating. Figure 5 shows ZTR as a function of rate for test temperature of $20^{\circ} \mathrm{C}$. 


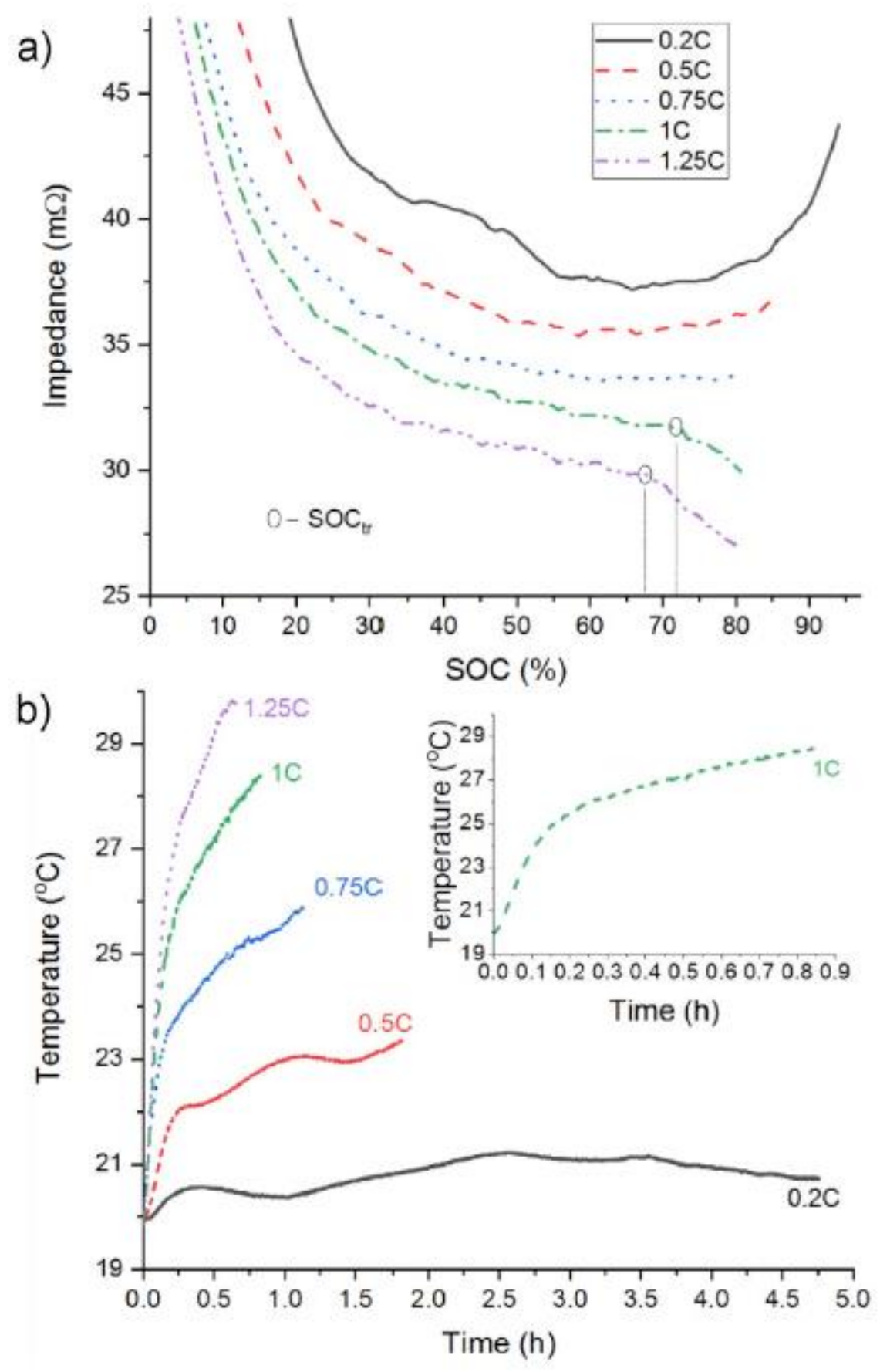

Figure 5. ZTR profiles without thermal cooling (a) ZTR profiles at different Crates and (b) temperature profiles measured on the cell surface. Reprinted from U.R. Koleti et al., Journal of Power Sources 451, 227798 (2020). Copyright (2020) with permission from Elsevier.

Three test cases are considered, A, B and C representing test temperatures of 10 , 20 and $30^{\circ} \mathrm{C}$ with active cooling and tested with the charge $\mathrm{C}$-rates $0.2 \mathrm{C}, 0.5 \mathrm{C}, 0.75 \mathrm{C}, 1 \mathrm{C}$, 1.25C. The EIS plots at different SOCs (Figure. 4b) and ZTR profiles in test cases A, B and $\mathrm{C}$ are taken at constant ambient temperatures in which impedances from Ohmic, SEI layer and electrolyte are assumed to remain constant. However, in practical applications, temperature rise during a charging event is inevitable which can increase the Ohmic 
resistance and decrease the impedances due to electrolyte, CTL and SEI layer. ${ }^{[36,40,54,175 \text {, }}$

${ }^{182]}$ Tracking the $Z_{C T L}$ and thus detecting Li plating may, therefore, become difficult in such cases. To track the ZTR under the scenarios of minimal cooling, the cells from test case D are charged in a large room maintained at $20 \pm 2{ }^{\circ} \mathrm{C}$, but with no active thermal management. In each charge event, different $\mathrm{C}$-rates are applied with pulse interruption procedure starting from $0.2 \mathrm{C}$ to $1.25 \mathrm{C}$. Figures $5 \mathrm{a}$ and $5 \mathrm{~b}$ shows the ZTR profiles and cell surface temperature variations on a cell at different charging $\mathrm{C}$-rates. The ZTR profile at $0.2 \mathrm{C}$ where the temperature rise is within $+1^{\circ} \mathrm{C}$ is similar to the one observed with active cooling. With the increase of C-rate, the effect of Li plating on ZTR profiles is clearly observed even with a temperature rise higher than $8^{\circ} \mathrm{C}$ for charge rates $\geq 1 \mathrm{C}$. The ability to detect Li plating using the ZTR profiles while temperature is also changing can be explained as follows. As seen from the inset plot in Figure $5 \mathrm{~b}$ for $1 \mathrm{C}$ charge rate, the majority of the temperature rise (circa $5^{\circ} \mathrm{C}$ rise of the total $8.2^{\circ} \mathrm{C}$ ) occurred during the first 10 min of the charging process and then the rate of temperature increase is reduced to circa $3.2^{\circ} \mathrm{C}$ rise over the next $39 \mathrm{~min}$. The authors ascribed the applicability of EIS method for Li plating under minimal cooling as follows: since Li plating typically occurs towards the end of CC charging where temperature changes are not assumed to be significant, temperature influence on the internal processes may be limited. Therefore, for the selected cell type and C-rates, Li-plating detection using the ZTR profiles is possible even under environmental conditions where temperature is increased during the charge process.

\section{$\underline{\text { Cell Thickness Measurement }}$}

Bitzer and Grule ${ }^{[36]}$ successfully employed cell thickness measurement to detect Li plating. It is based on the concept of anode (and cell) volume expansion. During the LiB charge/discharge process, the active materials vary in volume, depending on the degree of Li-ion intercalation. Graphite anodes, for example, gain about $10 \%$ in volume while changing from the de-lithiated elementary state to fully lithiated $\mathrm{LiC}_{6}{ }^{[185]}$. On the other hand, the cathode materials have a much smaller dilatation coefficient, for example, it is about $1 \%$ for $\mathrm{NMC}^{[186]}$. Therefore, generally the thickness of LiB is governed by the anode volume change. One exception is Li titanate anode (LTO), which has a negligible volume change of only $0.1 \%-0.3 \%{ }^{[186,187]}$. During charging, Li occupies the interstitials into the graphite lattice. Hence, the volume of the intercalation compound is smaller than the volume of the two separate materials. Li plating on the anode surface instead of intercalating into the anode leads to an additional gain in the overall volume. On the contrary, the de-intercalation from the cathode has no significant effect on the cell thickness. For $1 \mathrm{Ah}$ of charge from the cathode to the anode, the amount of Li transferred is:

$$
n_{L i}(1 A h)=\frac{C}{e . N_{A}}=37.31 \mathrm{mmol}
$$

nLi: amount of Li substance [mol], NA: Avogadro constant [1/mol], e: elementary charge [As]; C: transferred charge [As]. When the anode is fully charged, every six carbon atoms of graphite takes one $\mathrm{Li}$ atom. Thus for $1 \mathrm{Ah}$ of charge an amount of $6 . \mathrm{nLi}=223.9 \times 10^{-3}$ mol of carbon is consumed. With the molar volume of carbon in hexagonal structure of $5.31 \times 10^{-6} \mathrm{~m}^{3} \mathrm{~mol}^{-1}$ its volume is $1.189 \mathrm{~cm}^{3}$. According to the literature, carbon-based anode 
materials expand about $10 \%$ due to the intercalation of $\mathrm{Li}^{[185]}$. Thereby charging $1 \mathrm{Ah}$ causes a volume change of:

$$
\triangle V_{C}(1 A h)=\alpha_{L i C_{6}} \cdot n_{L i}(1 A h) \cdot 6 \cdot V_{m, C}=0.12 \mathrm{~cm}^{3}
$$

$\Delta \mathrm{V}_{\mathrm{C}}$ : Change of the carbon volume due to $\mathrm{Li}$ intercalation $\left[\mathrm{m}^{3}\right], \alpha_{L i C_{6}}$ coefficient of expansion changing from $\mathrm{C}$ to $\mathrm{LiC}_{6}=10 \%, \mathrm{~V}_{\mathrm{m}, \mathrm{C}}$ : molar volume of carbon $\left[\mathrm{m}^{3} \mathrm{~mol}^{-1}\right]$. Given the molar volume of $\mathrm{Li}$ is, $\mathrm{V}_{\mathrm{m}, \mathrm{Li}}=13.02 \times 10^{-6} \mathrm{~m}^{3} \mathrm{~mol}^{-1}$ the volume of $\mathrm{Li}$ corresponding to 1 Ah of charge is $0.49 \mathrm{~cm}^{3}$. In the case of Li metal disposition on anode surface, instead of intercalation, the resulting expansion equals the volume of the $\mathrm{Li}$ in metallic form minus the volume the anode would gain due to the intercalation, as shown in Equation (2).

$$
V_{e x p}\left(C_{p l}\right)=\frac{C_{p l}}{e \cdot N_{A}}\left(V_{m, L i}-\alpha_{L i C_{6}} \cdot 6 \cdot V_{m, C}\right)
$$

$\mathrm{V}_{\mathrm{m}, \mathrm{Li}}$ : molar volume of $\mathrm{Li}\left[\mathrm{m}^{3} \mathrm{~mol}^{-1}\right], \mathrm{V}_{\mathrm{m}, \mathrm{C}}$ : molar volume of carbon $\left[\mathrm{m}^{3} \mathrm{~mol}^{-1}\right] ; \mathrm{C}_{\mathrm{pl}}$ : amount of plated Li. According to Equation [C3], an amount of 1 Ah of plated Li causes a gain in volume of $\mathrm{V}_{\exp }(1 \mathrm{Ah})=0.37 \mathrm{~cm}^{3}$. Using this equation, it is possible to calculate the thickness of plated Li, knowing the surface area of electrode in the LiB. Thus, accurate measurement of cell thickness can serve to identify the onset of Li plating. Change of cell thickness during standard cycling showed that the volume change due to Li intercalation into graphite takes place in three steps with different slopes which is highly reproducible. When the battery is charged with high enough high current to cause Li plating, cell thickness increase could be observed. If the cell is at rest after plating, part of the plated Li intercalates into the graphite, causing some decrease in thickness. However, if excessive current is used, then the thickness growth persists indicating irreversible plating.

However, there are some practical challenges that affect the measurement accuracy. Due to cell inhomogeneity, dendritic deposition and gas evolution, the actual measured value is expected to be larger. Charging the cell with continuous currents leads to shifts in the $\Delta$ cell thickness vs Ah curve. Similarly, measurement temperature can interfere with accuracy. However, at a temperature increase of $1 \mathrm{~K}$ at the cell surface the thermal expansion is smaller than the resolution of the dial thickness indicator. In addition to the temperature effect, the measurement point of thickness causes also affects measurement accuracy. Due to an existing inhomogeneity within every cell, the position of the measurement point plays a crucial role. Many pouch cells are known to start plating in a narrow area next to the cell's margin. When choosing the wrong measurement point, the experiment could therefore fail to detect the onset of Li plating. The best point is always cell specific and must be determined prior to the thickness measurements, e.g., by opening the cell. Pouch cells especially have problems arising from Gas evolution originating from side reactions which interfere with accurate thickness measurement. Applying pressure on the cell by using appropriate spring can mitigate the problem and reduce the error. It was shown that during standard cycling other influences like the cathode expansion, temperature or gas evolution are small. 


\section{Optical Detection Methods}

The most common method to detect Li plating is to open the cell after cycling and look for Li deposit. Generally, the anode from the plated cell is inspected by one or more of the following techniques such as optical microscope, SEM, TEM, AFM, XPS, Raman etc. One challenge with these ex situ techniques is, the plated Li can also intercalate back into the graphite which sometimes makes it challenging to visually observe microscopic $\mathrm{Li}$ plating. Moreover, this method is conducted ex-situ which can introduce sample preparation error._Nevertheless, optical detection methods are effective tools to identify Li plating, its morphology and composition.

SEM investigations ${ }^{[188]}$ enable the analysis of plated $\mathrm{Li}$ and dendrites by both in situ and ex situ. Gireaud et al. ${ }^{[189]}$ observed dendrite growth on a $\mathrm{Li}$ surface at $20^{\circ} \mathrm{C}$ in $\mathrm{Li} / \mathrm{Li}$-coin cells $e x$ situ. Their work showed the influence of the surface structure on the dendrite growth. In contrast, Sagane et al. ${ }^{[188]}$ analyzed dendrite growth on copper under vacuum inside an in-situ SEM cell with a Li/LiPON/LATP/LiPON/Cu-configuration. They correlated the dendrite size with the applied current density. High current densities led to the formation of many small dendrites; low current densities led to the formation of fewer but larger dendrites. Steiger et al studied the growth of mossy Li by in situ light microscope and ex situ SEM. ${ }^{[190]}$ They found that the mossy Li form at the grain boundaries by the insertion of Li into defect sites. J. Guo et al studied the effect of $\mathrm{VC}-\mathrm{LiNO}_{3}$ additive on $\mathrm{Li}$ metal by EIS and ex situ SEM and XPS. ${ }^{[191]}$ They constructed a cell with Li and copper and used the electrolyte $1 \mathrm{M} \mathrm{LiPF}_{6} \mathrm{EC}_{\mathrm{DMC}}(1 / 1)$ as their baseline and studied the effect of additives, 2 vol.\% $\mathrm{VC}$ and $0.1 \mathrm{M} \mathrm{LiNO}_{3}$. It was found that the selected additive combination contributes to positive modifications of SEI film on the surface of Li anode in carbonate electrolyte system. Nearly $100 \%$ efficiency was observed for Li plating/stripping in the presence of these additives and a very homogeneous morphology of cycled Li were obtained.

Harris et al used in situ optical microscope detection of Li plating on a full operational cell and observed color change of graphite anode as a function of Lithiation. ${ }^{[8]}$ Uhlman et al ${ }^{[22]}$ also used an optical test cell-housing to observe the graphite anode in situ via confocal microscopy whilst applying current. They used a charging current of $10 \mathrm{C}$ for the test. They observed the color change of graphite with lithiation.

Depending on the SOC, the graphite changes its color from black, red, to gold ${ }^{[22]}$. This corresponds to the change of the band structure, due to the variation of the lattice spacing. Though this change happened very quickly in this measurement, due to the high charging current, it could be seen within the optical test-cell. After turning golden, which indicates the highest Li intercalation stage of graphite, a gray coating starts to cover the electrode. At the beginning of this process some small dots appear on the particles. Within 1-2 $\mathrm{s}$, the whole observation area is covered by a gray structure which is interpreted as a layer of metallic Li. When observing the frontier between plated and non-plated surface area during the relaxation phase, several facts were recognized. On one hand, the plated area decreases while the frontier of the two areas moves back. This is due to dissolution of plated $\mathrm{Li}$, since due to the decreasing Li surface concentration, intercalation becomes favorable over metallic Li. However, not all Li coverage is removed, a dark deposit remains on the location of the original plated $\mathrm{Li}$. The golden particles further change their color to brownish-red, indicating that they are not yet fully charged, and hence possess enough 
capacity to further intercalate Li. This supports the assumption that the dark deposit corresponds to irreversibly plated $\mathrm{Li}$ that will not be intercalated, even after extended relaxation periods. There are two possible explanations for the dark coloration: either the dark deposit consists of plated Li that lost electrical contact to the graphite during ongoing Li dissolution, or it consists of SEI-remnants of the plated $\mathrm{Li}$ on the surface. The exact origin cannot be determined, however since both effects lead to irreversible Li loss, both are undesirable in commercial cells.

A two-electrode cell was used for the optical detection in this work, instead of a three-electrode cell. Measurements have to be done using a reliable reference electrode, to measure the graphite potential without influence of the counter electrode. Also, this measurement is a representative measurement due to the size of the two/three electrode cell as opposed to the large EV cell. Therefore, it doesn't account for the temperature distribution and delta temperature of the big cell. Another drawback of optical detection method is that they are generally limited to imaging surface only. It is difficult to arrive at a quantitative estimation.

\section{Computer Tomography (CT)}

K.J. Harry et al used synchrotron hard X-ray microtomography on symmetric lithium/polymer/lithium cells. ${ }^{[192]}$ The polymer electrolyte was a polystyrene-blockpoly(ethylene oxide) copolymer mixed with lithium bis(trifluoromethanesulfonyl)imide (LiTFSI) salt. Computer tomography (CT) measurements allow high resolution imaging and are not surface limited but need to be performed with an optimal radiation power to avoid radiation damage. Consequently, highly optimized synchrotron measurements are necessary for two- and three-dimensional imaging of delicately structured metallic Li. The cells were first cycled 15 times at a low current density of $0.02 \mathrm{mAcm}^{-2}$, followed by cycling at a current density of $0.175 \mathrm{mAcm}^{-2}$ until the experiment was stopped for cell imaging or when the cell shorted. The imaging was performed using monochromatric hard X-rays with energies chosen in the $22-25 \mathrm{keV}$ range generated by the synchrotron. The X-ray shadow cast by the sample was converted into visible light using a scintillator. An optical microscope magnified this image and converted it into a digital image file. The sample was then rotated by a fraction of a degree and repeatedly imaged until 1,025 images were collected from the sample as it was rotated through $180^{\circ}$. The volume of dendrites was calculated by assuming each dendrite structure is composed of two half ellipsoid and measuring their length from the collected images. Their data show conclusively that under every dendritic structure there were subsurface structures located within the lithium electrode. In the early stages of dendrite formation, the volume occupied by the subsurface structure is significantly larger than that occupied by the dendritic structure protruding out from the electrode surface. This work indicates that preventing the growth of lithium dendrites may involve suppressing the nucleation of subsurface structures.

Later A. Yermukhambetova et al extended this method to explore the Li-S battery by 3D in situ X-ray tomography. ${ }^{[193]}$ They used a multi-scale, 3D X-ray imaging approach to examine an electrode both in situ at the micro-scale and ex situ at the nano-scale for a micron sized elemental sulfur and carbon black composite cathode. Sun et al used synchrotron in-line phase contrast X-ray CT to non-destructively visualize the evolution of 
electrodeposited lithium and observed separator rupture caused by their growth. ${ }^{[194]}$ O.O. Taiwo et al applied 3D X-ray CT to investigate the cycling graphite/Li half-cell in situ. ${ }^{[195]}$ Operando synchrotron X-ray CT enabled the real time 3D visualization of pit formation at the Li metal surface due to Li dissolution. Time-lapse laboratory X-ray CT imaging was used to track the growth of moss-like lithium deposits at the Li electrode surface over longer periods of cycling. The 3D imaging showed the appearance of pit-like holes on the Li metal surface as a result of Li dissolution during the first discharge, and the formation of a mossy, micro-structured lithium layer that increased in thickness with repeated cell cycling, penetrating the separator in the process. The results also highlight the importance of separator morphology in controlling or preventing dendrite growth in high tortuosity separators within commercial lithium batteries. One caution to be considered during measurement is the X-ray radiation dose to the cell samples must be carefully chosen to prevent material degradation and cell performance losses.

Recently R.F. Ziesche et al studied 4D imaging of primary lithium-batteries $\left(\mathrm{Li}_{\mathrm{x}} \mathrm{MnO}_{2}\right)$ using correlative neutron and X-ray tomography. ${ }^{[196]}$ The non-destructive nature of both X-ray and neutron CT provides opportunities for four-dimensional (4D) studies to explore the evolution of three-dimensional (3D) structures with time. After a series of data processing steps, these shadow images were converted to cross-sectional slices that were then stacked together to render a 3D reconstruction of the cell. Highly neutron-attenuating elements, such as $\mathrm{Li}$ and hydrogen, appear bright in the neutron tomograms, which facilitates detection of the Li anode between the darker cathodes of lower attenuation. X-ray CT allowed for the quantification of mechanical degradation effects such as electrode cracking from the electrode bending process during cell manufacturing. Whereas neutron CT gives information about the electrochemistry such as Li-ion transport and intercalation, electrolyte wetting of the cell and consumption or gas formation. The bulk properties that computational models were previously based on may now be replaced by spatially resolved, transient values. This technique offers the capability of incorporating local heterogeneities and would be able to provide a more accurate and comprehensive description of the practical operation, degradation and failure of a cell. Due to the electrolyte and $\mathrm{Li}$ having similar attenuation coefficients for neutrons, a direct correlation between the SOC and the amount of Li consumed could not be made, highlighting a limitation of this technique for the most commercially relevant cells.

\section{Nuclear Magnetic Resonance Spectroscopy}

Li NMR spectroscopy is a noninvasive method for investigating the structural changes that can occur in electrode materials, when performed in situ. ${ }^{[197-200]}$ The ${ }^{7} \mathrm{Li}$ signal ( spin $=3 / 2,92.5 \%$ abundance) can be acquired on a time scale that is much faster than the typical charge-discharge cycle. ${ }^{7} \mathrm{Li}$ NMR shows a chemical shift at $245 \pm 1 \mathrm{ppm}$ for pristine $\mathrm{Li}$ metal and at $>258 \mathrm{ppm}$ for plated Li. The structural changes that occur in the active material at various states-of-charge can be detected and quantified by recording spectra at suitable time intervals Nuclear magnetic resonance imaging (MRI) has proven to be capable of Li microstructure imaging, either directly or indirectly. 
Hsei et al studied ${ }^{7} \mathrm{NMR}$ on Li symmetric cell by both ex situ and in situ $\mathrm{NMR}^{[201]}$ to quantify irreversible lithium losses in batteries. Using NMR, GC-MS and calculations they distinguished losses due to SEI formation and fractions of dead lithium. revealing a distribution of different lithium metal microstructures on both working and counter electrodes upon plating and stripping. Using these combination techniques, they estimated dead lithium fractions of $3.3 \% \pm 0.6 \%$ (with $5 \%$ FEC) and $9.4 \% \pm 0.6 \%$ (without $5 \%$ FEC). NMR as a standalone technique can suffer from issues of sensitivity and selectivity. Its resolution is lower than with optical or electron microscopy techniques. In fact, resolutions below $100 \mu \mathrm{m}$ are hard to obtain for $\mathrm{Li}^{[186]}$. NMR method does not directly distinguish between the mossy and the dendritic Li structures.

Dynamic nuclear polarization (DNP) is another promising approach that uses $\sim 10^{3}$ times greater gyromagnetic ratio of paramagnetic electrons to hyperpolarize nuclear spins. In typical exogenous DNP experiments, organic radicals are added to the sample and it requires cryogenic sample cooling. The SEI on reduced graphene oxide and silicon anodes has been studied by exogenous DNP, whereby a solution of organic radicals is added to the system before cooling to $100 \mathrm{~K}$ or below, slowing the electron relaxation times of the radicals so that the ESR transition can be more easily saturated. ${ }^{[202-204]}$ This method has several limitations related to voltage instability of organic radicals, alteration of SEI by radicals, and it is not selective to SEI. Recently Hope et al achieved hyper polarization by irradiation of the conduction ESR (CESR) transition and partially equalizing the spin band. The electrons then cross relax with ${ }^{7} \mathrm{Li}$ nuclei in the metal, thereby inducing nuclear hyperpolarization. ${ }^{[205]}$ Selective enhancement of the SEI was observed in the diamagnetic ${ }^{7} \mathrm{Li},{ }^{1} \mathrm{H}$ and ${ }^{19} \mathrm{~F}$ NMR spectra, and the relative DNP enhancements allow the proximity of different species to the metal surface to be inferred. By using double resonance experiments they identified the components of the SEI such as polymeric organic species and LiF. Effect of electrolyte was evaluated by using electrolytes with and without the common additive fluoroethylene carbonate (FEC). Their experiments showed that appreciable ${ }^{7} \mathrm{Li}$ enhancements can still be achieved by Overhauser DNP under static conditions.

\section{$\underline{\text { Neutron Diffraction }}$}

Neutron diffraction offers a promising alternative to derive information about the processes within a Li-ion battery. In contrast to x-ray diffraction, it has the advantage of being sensitive to lighter elements (like Li, oxygen and nitrogen) and the high penetration depth of thermal neutrons makes it possible to investigate Li-ion cells in a non-destructive way. There are two approaches to neutron diffraction on Li-ion batteries: one is to build special in situ cells, optimized for the diffraction experiment(special geometry, deuterated electrolyte, etc. $)^{[25,26,206,207]}$. The other approach is to use commercial cells, with the benefit that electrochemical performance and balancing of the electrodes are optimized by the manufacturer. The detail method and instrument specification can be found in Ref. ${ }^{[40]}$.

Metallic Li in contact with the graphite anode is unstable; Li reacts with the graphite and diffuses into its interstitial spaces during intercalation. Even at $-20^{\circ} \mathrm{C}$, most of the metallic Li is intercalated after only $13 \mathrm{~h}$. This makes conventional studies on Li plating difficult: since the Li diffusion coefficient at $23^{\circ} \mathrm{C}$ is reported to be approximately six times the diffusion coefficient at $-15^{\circ} \mathrm{C}^{[38,208]}$, at room temperature at most possibly less $\mathrm{Li}$ 
remain to disassemble a cell or study $\mathrm{Li}$ plating by other methods. This fact further emphasizes the importance of using in situ techniques when Li plating is studied. Valuable insights into Li plating in commercial cells can be obtained by neutron diffraction.

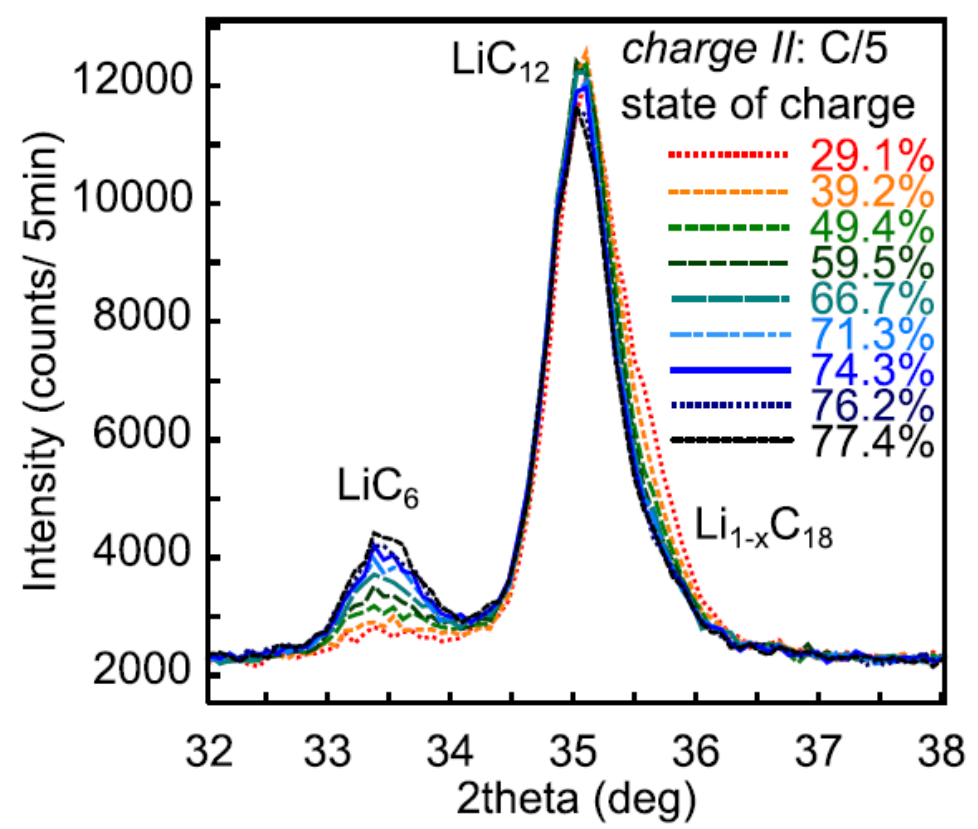

Figure 6: Diffraction data collected during $\mathrm{C} / 5$ charge at $-20^{\circ} \mathrm{C}(\mathrm{CV}$ phase begins after $57.3 \%$ SOC); data collected every 30 min are shown, SOC relative to nominal RT capacity. Reprinted from V. Zinth, C. von Lüders, M. Hofmann, J. Hattendorff, I. Buchberger, S. Erhard, J. Rebelo-Kornmeier, A. Jossen and R. Gilles, J Power Sources, 271, 152 (2014). ${ }^{[40]}$ Copyright (2014), with permission from Elsevier.

Zinth et al investigated the transformation of $\mathrm{LiC}_{12}$ to $\mathrm{LiC}_{6}$ during the charging process in detail. ${ }^{[40]}$ Intensities of the signal reflection of each of the two phases were analyzed, as described in Figure 6. It was shown that the loss of cyclable Li was significantly increasing for higher charge currents, when cells were operated at subambient temperatures of $-20{ }^{\circ} \mathrm{C}$, indicating that a considerable amount of $\mathrm{Li}$ has been deposited on the anode's surface. During a following rest period, the signal intensities of both phases changed, indicating a continuous intercalation of Li into the host structure, even after the applied current has been switched off. ${ }^{[40]}$

When the graphite anode is lithiated to more than $50 \%$, the two existing phases $\mathrm{LiC}_{6}$ and $\mathrm{LiC}_{12}$, commonly denoted as stage 1 and stage 2 in literature, show characteristic reflections at scattering angles $2 \theta$ for the $\mathrm{LiC}_{6}(001)$ at $33.53^{\circ}$ and for the $\mathrm{LiC}_{12}(002)$ at $35.04^{\circ}$. The intensity of the Bragg reflections increases with increasing share of the respective phase. Therefore, diffraction data in the range of $30^{\circ}-40^{\circ} 2 \theta$ were collected in 2 min throughout the experiment to follow simultaneously the strong (002) reflection of graphite and the similarly prominent reflections of the intercalation compounds $\mathrm{LiC}_{12}$ and $\mathrm{LiC}_{6}$ during the charging and relaxation. The integral intensity of the reflections was extracted by pseudo Voigt fitting of the data. In case of overlapping reflections, the full width at half maximum (FWHM) was refined once for all reflections. 
The plated Li was compared with the voltage relaxation peaks. The changing peak intensities match distinctly with the voltage relaxation behavior, measured at the cell terminal. It can be observed that the amount of plating Li correlates nonlinearly with the charging rate, whereas a charging current of $\mathrm{C} / 2$ leads to a deposited amount of $\mathrm{Li}$ of $5.5 \%$ and a current of $1 \mathrm{C}$ to $9.0 \%$ of the charged capacity. Above a threshold current of $\mathrm{C} / 5, \mathrm{Li}$ plating increases dramatically. The results indicate that the intercalation rate of reversibly deposited $\mathrm{Li}$ seems to be constant, independent of the deposited amount, and that the duration of the voltage plateau during the relaxation period can be used as an indicator for deposited Li.

\section{Electron Paramagnetic Resonance}

Electron Paramagnetic Resonance Spectroscopy (EPR), is a non-invasive and highly specific technique capable of detecting unpaired electrons or radicals. Though EPR has been successfully used in other fields it gained interest in the $\mathrm{LiB}$ recently. It is a powerful tool for characterizing the formation and disappearance of radical oxygen species during the cycling of a battery. EPR offers unprecedented opportunities to study highcapacity electrode materials. With EPR imaging (EPRi), it is possible to view the electrondensity distribution in materials, if we can develop EPR imaging (EPRI). The electrochemical cell for the study should be made up of a material that is (i) compatible with all cell components (electrolytes, electrodes and so on), (ii) transparent to microwave radiation and (iii) inactive for EPR.

Electron paramagnetic resonance (EPR) spectroscopy is more sensitive than nuclear magnetic resonance, while still employing low energy radiation that does not affect the chemical properties or the morphology of the investigated samples. Conduction EPR (CEPR) has been carried more than 50 years ago for the detection of conduction electrons in metallic $\mathrm{Li}^{[209,210]}$. Recently there has been a growing interest for the in operando study of Li plating in a $\mathrm{LIB}^{[30]}$ and the quantitative analysis of Li plating on graphite ${ }^{[31]}$, both are very challenging with alternative techniques. Sathiya et al first designed a special EPR electrochemical cell for in situ characterization. ${ }^{[11]}$ The cycling profile of $\mathrm{Li}_{2} \mathrm{Ru}_{0.75} \mathrm{Sn}_{0.25} \mathrm{O}_{3}$ electrode versus Li was studied by collecting and analyzing the EPR image of the cathode material. In the cathode material $\mathrm{Ru}^{5+}, \mathrm{O}_{2}{ }^{3-}$ and $\mathrm{O}_{2}{ }^{-}$are EPR active and $\mathrm{Ru}^{4+}$ and $\mathrm{O}_{2}{ }^{2-}$ are EPR inactive. As the change in the oxidation state of cathode components changes their EPR activity, it is possible to monitor the charge/discharge cycling by EPR and EPR image. Similarly, by CEPR method, Li morphology could also be distinguished from the linewidth of the metallic Li signal, with porous Li showing a much narrower EPR line than bulk Li, as can be seen in Figure 7. Therefore, CEPR is a sensitive indicator for the dimensions of the Li structures.

Neimöller et al used CEPR to study dendrite growth on separator. ${ }^{[212]}$ They explained how the EPR line shape serves to distinguish different kinds of Li morphologies. EPR of conductive samples are influenced by the skin effect, which leads to a depth dependent attenuation and sample thickness dependent phase shift of the EPR signal ${ }^{[211,}$ 213]. The skin depth is about $\delta \approx 1.1 \mu \mathrm{m}$ for metallic $\mathrm{Li}$ at $\mathrm{X}$-band microwave frequencies. When the sample thickness $\mathrm{d}$ is larger than the skin depth $\delta$, the experimentally acquired first derivative EPR spectrum shows a Dysonian lineshape that can be approximated by a 
phase-shifted Lorentzian ${ }^{[209]}$. The resolution achievable in an EPRI experiment is similar to that of MRI ${ }^{[214,215]}$, which depend on the full width at half maximum of the point spread function $^{[216]}$. The EPR linewidth in the absence of a magnetic field gradient and the applied imaging gradient determine the image resolution. The pixel or voxel length $\Delta z$ of the EPR image is proportional to the EPR peak-to-peak linewidth $\triangle \mathrm{Hpp}$ and to the inverse of the gradient $\mathrm{G}^{[217]}$, narrower lines and stronger gradients allow for higher resolution images.

$$
\triangle Z \propto \frac{\triangle H_{P P}}{G}
$$

[EPR 1]

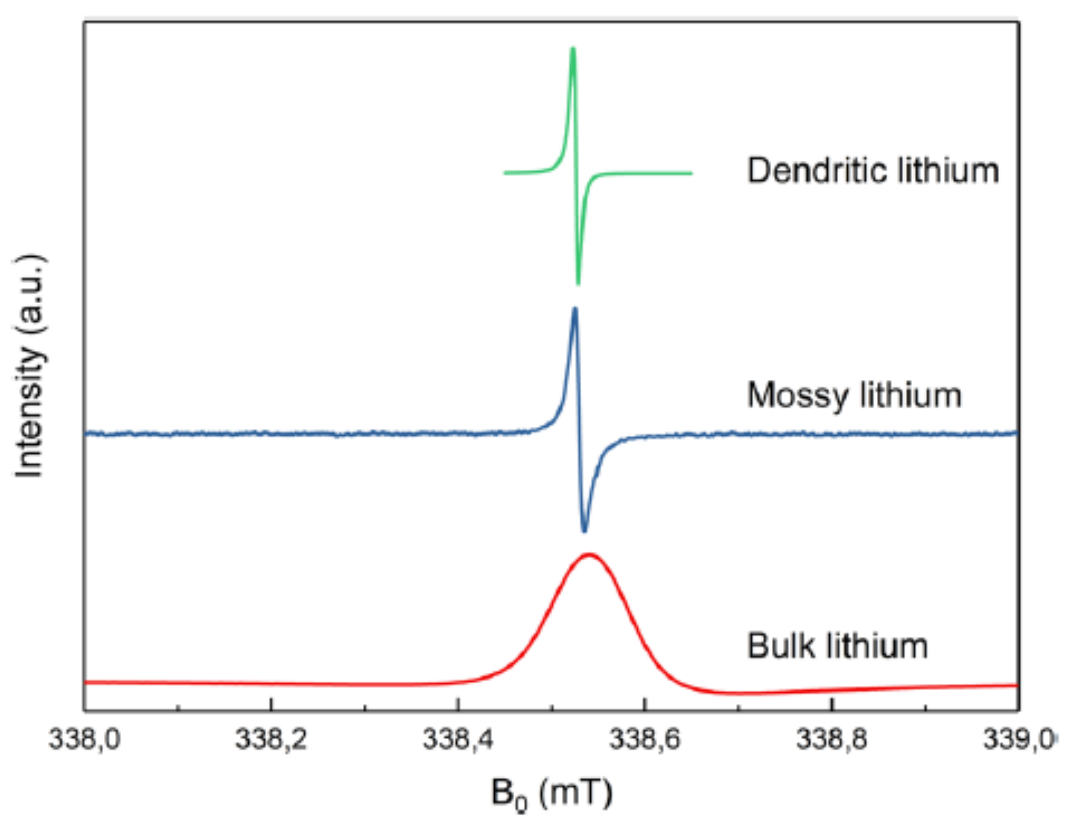

A. Figure 7: First derivative CEPR signal, as measured in a field swept EPR experiment, for metallic Li with different morphologies. The peak-to-peak linewidth for dendritic Li with ca. $0.005 \mathrm{mT}$ (green), mossy Li is $0.03 \mathrm{mT}$ (blue) and bulk Li is ca. $0.15 \mathrm{mT}$ (red). Reproduced from Neimöller et al Scientific

Reports, 8, 14331 (2018). ${ }^{[212]}$. (CC BY, https://creativecommons.org/licenses/by/4.0)

The self-diffusion of spin-carrying conduction electrons changes the linewidth. As the spin depth is much bigger than the skin depth, electrons diffuse from the surface into the bulk of the material. As a result, excited electron spins are withdrawn from a region excited by the external microwave field and replaced by electrons with an equilibrium spin state ${ }^{[210]}$. This process leads to a line broadening. Therefore, when a narrow dendritic line is observed, all the spins are contained in structures that are fully penetrated by the microwave field, hence quantitative imaging of the spin density is possible. This imaging method shows great potential for imaging of Li dendrite growth within solid electrolytes. Quantitative in situ application of CEPRI faces a challenge of multiple peaks from different $\mathrm{Li}$ morphologies and other paramagnetic species. 
Accelerated Rate Calorimetry (ARC)

Similar to chemical reactions, electrochemical reactions have thermal signatures ${ }^{[218,}$ ${ }^{219]}$. Sample temperature variations alter the kinetics of redox processes and material properties that influence mass transport such as electrolyte viscosity. These temperature variations can permit undesirable outcome such as Li plating and excessive solidelectrolyte interphase (SEI) growth. Low temperatures, high charging rates (C-rates), and spatial thermal gradients are known to enable Li plating ${ }^{[46]}$. High temperatures accelerate SEI growth and diminish performance. On the cell level, a measure for cell safety is the onset temperature of exothermic reactions in accelerated rate calorimetry (ARC) tests. In ARC tests, cells are heated step-by-step under quasi-adiabatic conditions until exothermic reactions are detected (heat-wait-seek experiment).

Carter el evaluated three fully charged cells by ARC to assess their thermal runaway ${ }^{[220]}$. One cell was conventionally cycled equilibrium $20^{\circ} \mathrm{C}$ and it began to selfheat at $130^{\circ} \mathrm{C}$. The second cell was cycled at equilibrium $0{ }^{\circ} \mathrm{C}$ and the third was cycled with transient 40 to $0^{\circ} \mathrm{C}$. The latter two cells began to self-heat at low temperatures 50 and $35^{\circ}$ $\mathrm{C}$, respectively. The higher peak temperature of the transient 40 to $0{ }^{\circ} \mathrm{C}$ cell $\left(154{ }^{\circ} \mathrm{C}\right.$ compared to $108{ }^{\circ} \mathrm{C}$ for the Equilibrium $0{ }^{\circ} \mathrm{C}$ condition) caused by $\mathrm{Li}$ side reactions, indicates a greater quantity of metallic $\mathrm{Li}$, augmenting the heat generation. Since venting is not evident in the data for each of these cells, both cans rupture during the thermal runaway event, releasing active material. In the case of the equilibrium $0{ }^{\circ} \mathrm{C}$ cell, the jellyroll ejects through the top of the cell whereas the transient 40 to $0{ }^{\circ} \mathrm{C}$ cell exhibits side wall rupture opening the cell in the radial direction. In contrary, the conventional $20^{\circ} \mathrm{C}$ cycled cell didn't have any rupture, although it also combusted after $200^{\circ} \mathrm{C}$.

Charging Li-ion cells under spatially uniform, temporally transient thermal conditions can greatly reduce performance and safety. A single charging of a commercial Li-ion battery while its temperature is decreasing temporally toward $0{ }^{\circ} \mathrm{C}$, is enough to cause Li plating and early loss of capacity, earlier onset temperature of thermal runaway, and higher heat generation temperature during thermal runaway. The 18650 cells examined show evidence that approximately half of the $\mathrm{Li}^{+}$ions transferred in this first charge deposit as Li metal rather than intercalating in both the mild transient 10 to $0{ }^{\circ} \mathrm{C}$ and the more substantial transient 40 to $0{ }^{\circ} \mathrm{C}$ cases. When this substantial plating is induced by the transient thermal condition, a depression in the charge voltage to a negative differential voltage occurs. However, after the cells reach $0{ }^{\circ} \mathrm{C}$, stripping was still observed on the discharge, but the charge voltage does not exhibit a negative differential. The distinct nature of this feature provides a route for detection of the onset of this aggressive Li plating behavior with BMS algorithms. Since cells charged during the transient to $0{ }^{\circ} \mathrm{C}$ experience significant Li plating and subsequent stripping, its long-term performance differed from a cell initially equilibrated to the same condition. The equilibrium $0 \circ \mathrm{C}$ cell undergoes significantly less Li metal plating and stripping $(\sim 0.2 \mathrm{Ah})$ but eventually experienced jellyroll collapse after $\sim 30$ cycles due to low temperature. However, the largest quantity of Li plated and stripped in the transient 40 to $0{ }^{\circ} \mathrm{C}$ case $(1.04 \mathrm{Ah})$ which caused the jellyroll to collapse more rapidly, after only $\sim 5$ cycles. These distinct degradation modes enable extremely energetic failure modes following self-heating at mild temperatures of only 50 
and $35{ }^{\circ} \mathrm{C}$ for the equilibrium $0 \circ \mathrm{C}$ and transient 40 to $0 \circ \mathrm{C}$ cases, respectively. The Transient 40 to $0{ }^{\circ} \mathrm{C}$ case shows evidence of more residual Li metal and a more rapid acceleration to thermal runaway leading to can wall breaches.

The cells' sensitivity to thermal transient conditions emphasize the need to understand the correlations between Li-ion battery environments and local electrochemistry. This understanding can better evaluate safe operating conditions and thermal management strategies. The thermal sensitivity of form factors and pack assemblies should be evaluated. Moreover, it is important to understand the time to equilibrium when selecting C-rate, so that substantial SOC variation does not occur during a thermal transient condition. These considerations are particularly important for extreme fast charging. One main drawback of the ARC study is, the instrument is commonly designed to study small cells, such as 18650 or 26650 sizes. In order to study bigger EV cells, it must be custom designed for safe measurement which increases the cost.

\section{$\underline{\text { In Operando Acoustic Detection of Li Metal Plating }}$}

Non-destructive methods for detecting localized Li metal plating in LiBs have been challenging to set up. An elegant and straightforward method is to correlate cell thickness measurements with plating in operando ${ }^{[221,222]}$. Although this is a proven method, it is unable to distinguish between gassing reactions and Li metal plating, which may both increase cell thickness. Earlier report by Hsieh et al. introduced the ability of acoustic ultrasound to probe physical dynamics of a battery during cycling ${ }^{[223]}$. Specifically, Davies et al. ${ }^{[224]}$ attributed the shifts in the transmitted ultrasonic signals due to variations of the electrode density and bulk modulus. Similarly, Gold et al. ${ }^{[225]}$ utilized a comparably lower frequency ultrasonic pulse (200 KHz versus $2.25 \mathrm{MHz}$ ) to analyze the arrival time of the slow, compressional wave. J.B. Robinson et al studied a commercial cell phone battery by successfully employing spatially resolved ultrasound acoustic measurement combined with X-ray computed tomography. ${ }^{[226]}$ They demonstrated the applicability of this method for battery state of health measurement and also identified local cell construction glitches associated with anode tab. Z. Deng et al along with Jeff Dahn have successfully demonstrated cell wettability differences in pouch cells by employing ultrasonic scanning technology ${ }^{[227]}$.

Bommier et al. ${ }^{[228]}$ demonstrates that the simple and scalable in operando acoustic technique can be utilized to detect Li metal plating in commercial scale LiBs. The detection method is semiquantitative, as more significant Li metal plating results in increased hysteresis of the acoustic time of flight. The acoustic technique can observe localized and heterogeneous plating events, because the signal comes from the total acoustic pathway between the locations on the cell connected to the transducers. Moreover, the technique can be deployed with minimal start-up costs, requiring transducers, an acoustic detector, and an open source software package.

Bommier et al studied the cycling of the $\mathrm{LiCoO}_{2} /$ graphite battery cell. The first two $\mathrm{C} / 15$ cycles show a clear Time Of Flight (TOF) shift, with the TOF decreasing during the charging step and increasing during the discharge step. Graphite has a larger volumetricspecific capacity than $\mathrm{LiCoO}_{2}$ (LCO), therefore it takes up a larger portion of the acoustic pathway and will have a greater impact on the TOF. The local inflection points in the TOF 
shift may be due to graphite staging events, as these are located at the same SOC as inflection points in the voltage curve. The TOF shifts for the initial slow C/15 charge and the faster fixed capacity charge were compiled for all tests and analyzed. As described in Figure 8 , the acoustic TOF shift between the $\mathrm{C} / 15$ current rate (blue curve) and the $0.5 \mathrm{C}$ fixed capacity charge (red curve) is similar. However, as the current rate is increased to $0.75 \mathrm{C}$ and $0.88 \mathrm{C}$, the respective TOF shift between the slow charge and the faster fixed capacity charge begins to deviate (Figures $8 \mathrm{~B}$ and $8 \mathrm{C}$ ). At the current rate of $1 \mathrm{C}$, there is a clear anomaly that develops within the cell at around 0.070 Ah: the initially decreasing TOF shift suddenly reverses course and starts to increase. When the fixed capacity charge is finished, the TOF shift is completely different from that of the slow rate $\mathrm{C} / 15$ charge, with a large difference in the endpoints (Figure 8D). These results indicate the possibility of using the TOF endpoint difference as a plating detection parameter.
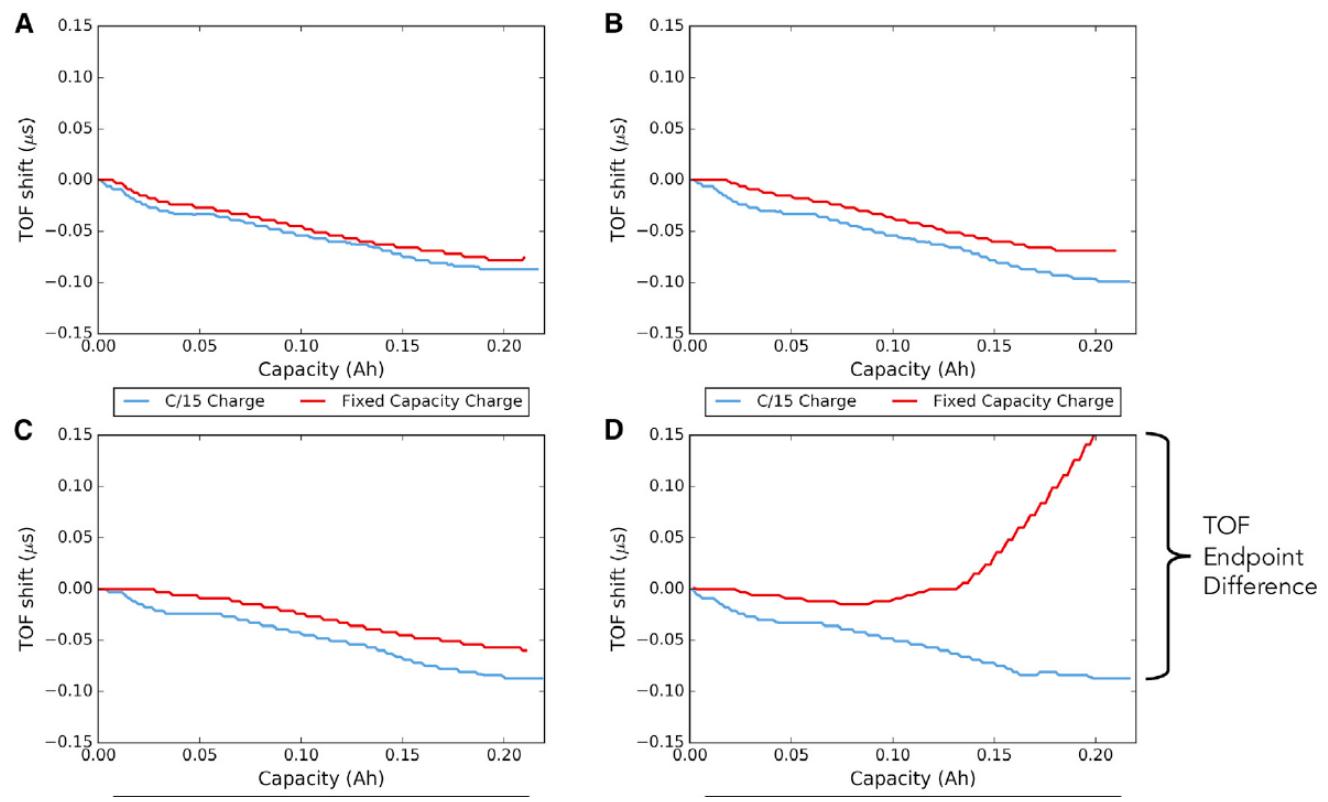

Figure 8. Comparison of acoustic TOF shifts during the $\mathrm{C} / 15$ charge and the fixedcapacity charge of $0.210 \mathrm{Ah}$, at four different current rates. No voltage cutoffs were set for fixed-capacity charges. These cells were cycled at $10^{\circ} \mathrm{C}$ with a fixed capacity charge of (A) 0.5C, (B) 0.75C, (C) 0.875C, and (D) 1C. Reproduced from C. Bommier et al, Cell Reports Physical Science 1, 100035, (2020) ${ }^{[228]}$. (CC BY, https://creativecommons.org/licenses/by/4.0) 
A
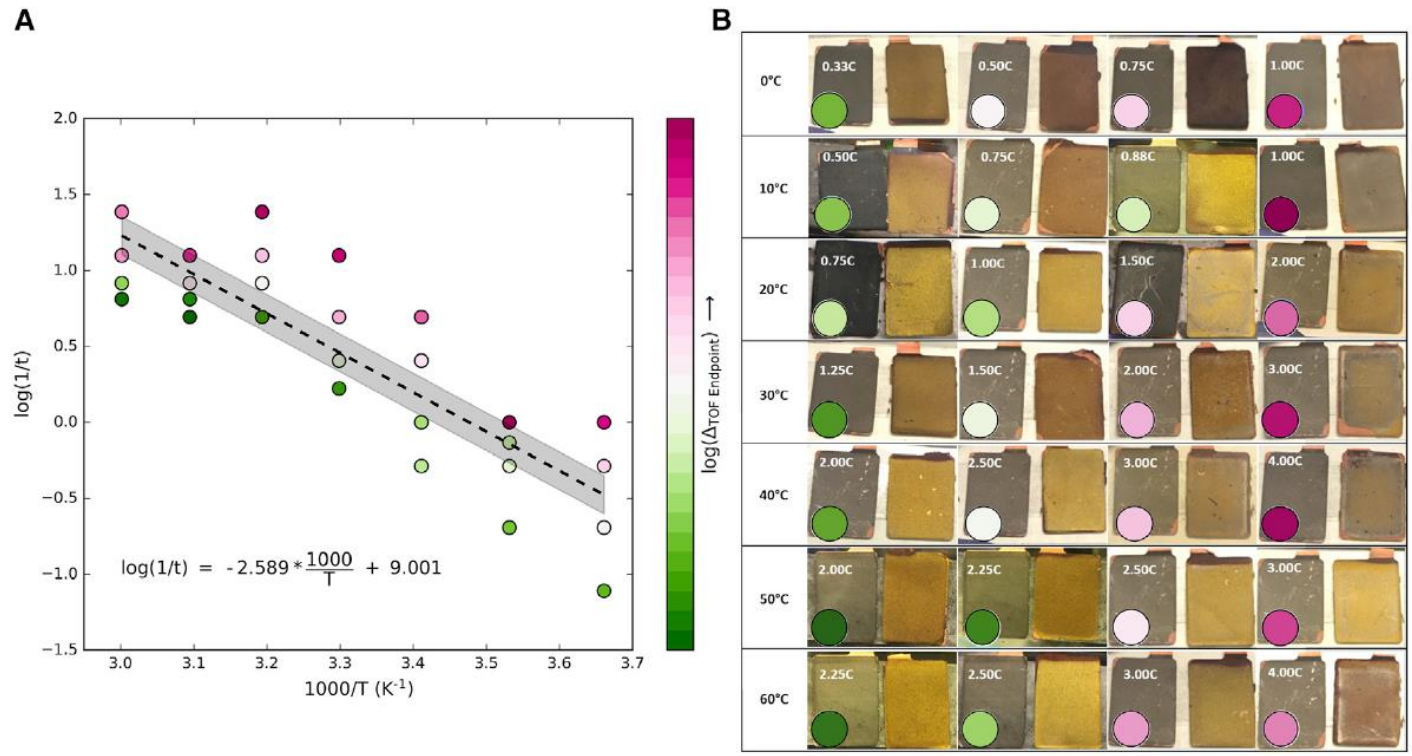

Figure 9: (A) Plot of logarithmic rate (1/t) versus inverse temperature $(1,000 / T)$, using the associated color bar to factor in the time of flight (TOF) endpoint difference between the $\mathrm{C} / 15$ charge and the fixed capacity charge. (B) Optical images of a delithiated graphite anode control (left of image) and the anode at the corresponding fixed-capacity charge (right of image). The colored dot represents the TOF endpoint difference according to the color bar used in (A) ${ }^{[228]}$. Reproduced from C. Bommier et al, Cell Reports Physical Science 1, 100035, (2020). (CC BY, https://creativecommons.org/licenses/by/4.0)

Figure 9 shows the plot of logarithmic rate versus inverse temperature. A symmetric logarithmic color bar has been used for easier identification of TOF endpoint differences. Lower TOF endpoint differences are indicated by an increasingly dark green color, and higher TOF endpoint differences are indicated by an increasingly dark magenta color. The depicted equation represents the linear fit (Arrhenius relationship) between logarithmic rate and inverse temperature, shown by the dotted line. The gray error bar represents the statistical standard error, which is the variance of the dataset divided by the set size. TOF endpoint differences generally increase with rate at any given temperature, as visualized by the color of the datapoint. Because plating is a continuum event, the linear fit generally describes conditions where plating is likely (i.e., one standard deviation above the linear fit) but does not conclude with certainty the presence of plating due to the statistical nature of this experiment. With a pouch cell that had undergone visible gassing and swelling, the permanent attenuation of the acoustic signal can be observed. Acoustic waveforms are known to propagate much more easily through solid or liquid mediums due to a lower impedance mismatch ratio, and significant attenuation of the signal implies the presence of gassing.

One drawback of the technique as it currently stands is the bulk methodology. A simple ultrasonic pulse through the length of the battery allows for a quick assessment of the entire stack. At the same time, it also convolutes contributions from individual electrodes. Therefore, it would be difficult to distinguish whether plating occurred on only one or 
several electrodes and determine which electrodes plated. The acoustic effects are solely based on the area between the transducers, so to identify spatial heterogeneities, multiple transducers can be placed on a single cell, given that it is large enough. This makes for useful commercial cell quality analysis, especially owing to the low cost and speed at which diagnostics can be carried out. As the wavelength of the ultrasonic pulse is relatively low, on the order of $\sim 1 \mathrm{~mm}$, there may exist a minimum resolution beyond which plating cannot be detected (e.g., single-layer electrode pouch cells). However, W. Chang et al demonstrated the sensitivity of thickness detection can be improved to micron resolution when combined with in-situ transmission X-ray microscopy (TXM). ${ }^{[229]}$ They combined the ultrasound acoustic detection with TXM to study the expansion and contraction of a pouch cell during cycling. Their expectation is that TXM has sufficient range and pixel resolution to measure both the total cell thickness and the average layer thicknesses, though it proved to be more difficult to image. Nevertheless, they successfully measured the effective stiffness of a commercial pouch cell battery during cycling from the wave velocity and cell thickness in operando by the TXM/acoustics setup. Note that cell stiffness is resulting from electrode expansion during cycling. Lastly, the acoustic detection sensitivity is also related to the attenuating properties of the media. Form factors that include materials that have higher impedance mismatch with the transducers or that intensify waveform convolution (e.g., springs/spacers in coin cells) may be more difficult to analyze.

\section{Mass Spectrometry Titration}

Recently Mass spectrometry titration (MST) is successfully employed for inactive Li quantification on graphite with a detection limit of $20 \mathrm{nmol} \mathrm{Li}$, which corresponds to 0.5 $\mu \mathrm{Ah}$ of total plated $\mathrm{Li}^{[48]}$. This technique is a modified version of a similar titration ${ }^{[230,231]}$. to quantify $\mathrm{Li}_{2} \mathrm{CO}_{3}$ on extracted $\mathrm{Li}-\mathrm{O}_{2}$ battery cathodes and was recently used to quantify surface $\mathrm{Li}_{2} \mathrm{CO}_{3}$ on Li-rich and Li-stoichiometric NMC cathodes. With the MST, it was possible to precisely identify: 1) the charge rate at which Li plating is observed if the electrode is charged to its nominal full capacity (corresponding to $372 \mathrm{mAh} / \mathrm{g}$ graphite), and 2) the state of charge at which Li plating commences at a $4 \mathrm{C}$ rate (full charge in 15 minutes). It can be characterized by an electrochemical model to determine the Li plating exchange current density and the efficiency of plated Li stripping during discharge.

M.J. Shane et al, used MST to quantify plated and inactive $\mathrm{Li}^{[208]}$ The graphite electrode sample was first placed in an airtight titration vessel, the apparatus and the method are described previously. ${ }^{[48]}$ A Labview program was used to sample gas from the vessel headspace every two minutes, replenish Argon to the vessel after sampling, and record ion currents, pressure, and temperature throughout the experiment. While the Labview program was running, $3.5 \mathrm{M} \mathrm{H}_{2} \mathrm{SO}_{4}$ was injected with an airtight syringe through the septum port on the titration vessel. Previous work on quantification of $\mathrm{Li}_{2} \mathrm{CO}_{3}$ on cathode materials $^{[232]}$ using the same MST setup showed that any concentration above $1 \mathrm{M}$ $\mathrm{H}_{2} \mathrm{SO}_{4}$ provided sufficient excess acid to react all present carbonate species, and $\mathrm{H}_{2} \mathrm{SO}_{4}$ was chosen over other acids to remain consistent with similar previous carbonate titration studies $^{[230,231]}$. Carbonate titrations using phosphoric acid have also been reported and yield similar results ${ }^{[233]}$. The maximum amount of gas evolved in any single experiment was roughly $15 \mu \mathrm{mol}$, which is calculated to cause a pressure increase in their sealed titration vessel $\sim 30$ torr, not large enough to break the titration vessel. An inert gas should be used 
as the carrier gas to ensure evolved $\mathrm{H}_{2}$ does not combust given the high exothermicity of Li reacting with acid or water.

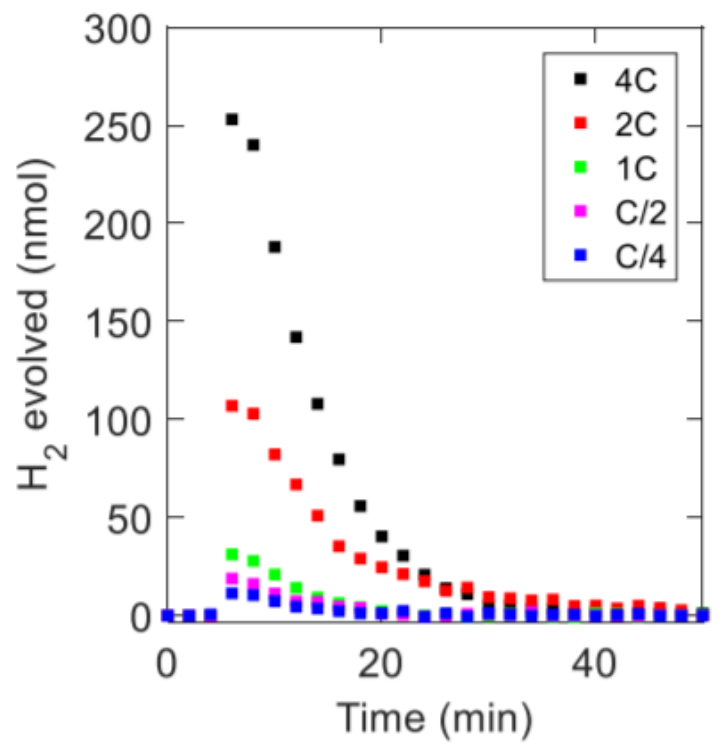

Figure 10: $\mathrm{H}_{2}$ gas evolution during titration. Acid was injected before the fourth data point in each case ${ }^{[48]}$. Reproduced with permission from E.J. McShane et al, ACS Energy Lett., 5 (6) 2045-2051 (2020). ${ }^{[208]}$ Copyright (C) 2020 from American Chemical Society

As can be seen in Figure 10, It is possible to achieve a detection limit of 20 nmol inactive $\mathrm{Li}$ with MST, which is based upon the expected minimum $\mathrm{H}_{2}$ signal that can be quantified upon titration. One mole $\mathrm{H}_{2}$ corresponds to 2 moles of inactive Li. The lowest amount of inactive Li measured with MST was $105 \mathrm{nmol} \mathrm{Li}$, which is much higher than the signal to noise. An evolution of $\sim 5 \mathrm{nmol} \mathrm{H}_{2}(\sim 10 \mathrm{nmol}$ of inactive Li) would still be perceptible, although not quantifiable. $10 \mathrm{nmol}$ of $\mathrm{H}_{2}(20 \mathrm{nmol}$ inactive $\mathrm{Li})$ is clearly distinguishable from baseline noise, as scaling the $105 \mathrm{nmol}$ inactive Li data by 1/5.

Inactive $\mathrm{Li}$ includes only electronically isolated $\mathrm{Li}$ and $\mathrm{Li}_{\mathrm{x}} \mathrm{C}_{6}$. It can be calculated by assuming that plated $\mathrm{Li}$ is formed via a 1 electron/ $\mathrm{Li}$ process and $\mathrm{Li}_{\mathrm{x}} \mathrm{C}_{6}$ is formed via a $\mathrm{x}$ electron/Li $\mathrm{L}_{\mathrm{x}} \mathrm{C}_{6}$ process, i.e., 1 mole electron per mole inactive Li. This calculation is shown below, where $\mathrm{Q}_{\mathrm{Li}}$ is the inactive $\mathrm{Li}$ equivalent capacity and $\mathrm{nLi}$ is the number of moles of inactive $\mathrm{Li}$ measured via $\mathrm{H}_{2}$ evolution upon titration:

$$
Q_{L i}=n_{L i} \frac{1 \mathrm{~mol} e^{-} 96485 \mathrm{CmAh}}{1 \mathrm{~mol} \mathrm{Limol} e^{-3.6 C}}
$$

Contribution of each Source of capacity loss is shown in Figure 11. Solid carbonate and $\mathrm{Li}_{2} \mathrm{C}_{2}$ contribution to total irreversible capacity are calculated based on the increase in their amount above the baseline values observed after formation cycling. Thus, mass spectrometric titration is a powerful technique in distinguishing between inactive $\mathrm{Li}$ and other surface components of plated Li. However, this technique is ex situ, which require tearing down the cell for analysis. The accuracy of the estimation depends on the time between tear down and analysis as with other ex situ techniques. 
b)
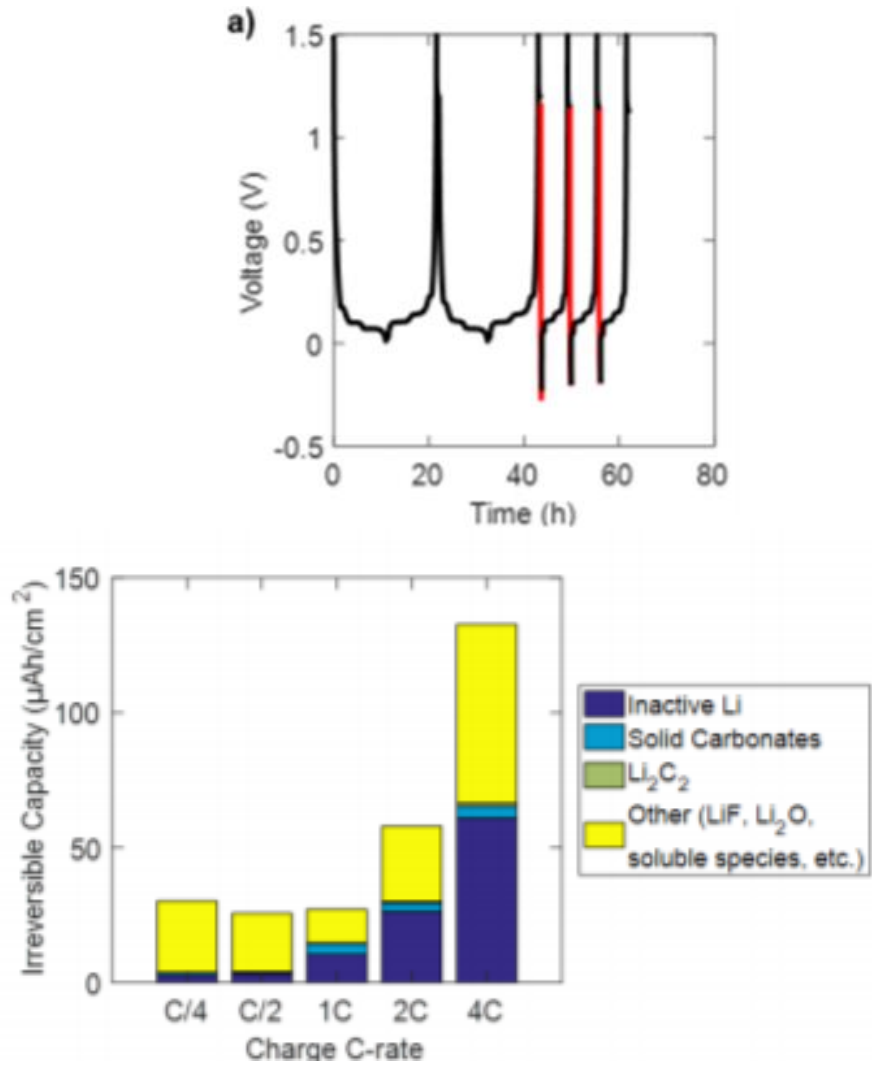

Figure 11: (a) Cell cycling procedure: two $\mathrm{C} / 10$ formation cycles $(0.010-1.5 \mathrm{~V})$ followed by three cycles of varying charge rate (shown in red) and $\mathrm{C} / 4$ discharge to $1.5 \mathrm{~V}$ with 30-minute OCV period between each charge/discharge. (b) Total contributions of inactive $\mathrm{Li}$, solid carbonate, $\mathrm{Li}_{2} \mathrm{C}_{2}$ and other species to the observed irreversible capacity after three cycles of varying charge C-rates from $(\mathrm{a})^{[48]}$. Adapted with permission from E.J. McShane et al, ACS Energy Lett., 5 (6) 2045-2051 (2020). ${ }^{[208]}$ Copyright (@ 2020 from American Chemical Society

\section{$\underline{\text { Summary and Outlook }}$}

Anode Li plating is one of the main factors that result in rapid aging and safety issues of LiBs; addressing this issue is critical to design safer and more durable LiBs. This paper presents an overview of existing methods and recent advancements in the detection of anode Li plating. The review covers the underlying mechanisms of Li plating, diagnostic techniques, their benefits and the current status of development.

Li deposition is more likely to happen with decreasing temperature, increasing SOC and increasing charging $\mathrm{C}$-rate However, the interplay of these main factors is also important. Low temperatures do not lead to Li deposition in all cases, however, if certain limits of SOC and/or charging C-rate are exceeded. For example, a cell might be charged by high currents at low SOC and later by lower currents without Li deposition. At low temperatures, the Li deposition might be suppressed by low charging currents or by preheating of batteries. Variations can be observed when inhomogeneities/gradients are present inside the cells: temperatures, SOCs and current densities. Such variations can lead to a variety of macroscopic morphologies for $\mathrm{Li}$ deposition, including, homogeneous $\mathrm{Li}$ 
deposition (Li plating), local Li deposition and marginal Li deposition As an example, local formation of gas bubbles or SEI growth and clogging of pores at high temperatures can lead to local $\mathrm{Li}$ deposition during cycling at $45^{\circ} \mathrm{C}$.

Besides these evidences for Li metal deposition in Li-ion cells, a variety nondestructive and destructive methods exist which are based on ageing behavior, analysis of electrochemical data, cells, and electrodes. Besides ageing mechanisms, Li deposition is also connected to safety mechanisms. Two main safety mechanisms were identified including, internal shorts caused by the dendritic growth of $\mathrm{Li}$ and exothermic reactions of $\mathrm{Li}$ with electrolyte The dendritic growth of $\mathrm{Li}$ is connected to the $\mathrm{Li} / \mathrm{Li}^{+}$interaction on the atomic level, the presence of ridges, and higher field densities at the tips of the dendrites. Besides the very low probability of failures due to Li dendrites in Li-ion cells (ppm range) they are relevant, and some attempts have been made for failsafe designs and early detection of dendrites. Exothermic reactions of Li metal with electrolyte can already start at $30-35{ }^{\circ} \mathrm{C}$ under the adiabatic conditions of ARC tests. In an application this translates to a situation, when not enough heat can be transferred from the cell to the surroundings, i.e. for a very high thermal isolation. This shows the importance of cooling systems for batteries in applications.

It is challenging to sensitively and quantitatively detect anode Li plating in practical LiBs, which is significant for battery management systems. The cause of anode Li plating depends strongly on the cell design and operating conditions, especially charge rate and temperature. During high-rate charging at room temperature, the poor solid phase diffusion of $\mathrm{Li}$ ions is responsible for anode Li plating. As the temperature decreases, the interface reaction is also hindered in addition to solid phase Li diffusion. In order to suppress anode Li plating, optimizing the electrolyte composition and modifying the graphite surface structure by methods such as coating, and doping are usually employed. In addition, appropriate working conditions and charging protocols can reduce the possibility of anode Li plating. A recent report from Yang et $a l^{[234]}$ described the performance of self-heating LiB structure which has thin nickel $(\mathrm{Ni})$ foils embedded inside a cell that can create immense and uniform heating. The $\mathrm{Ni}$ foil is an inherent component of a single cell along with electrodes and electrolyte. It serves as an internal heating element, as well as an internal temperature sensor as its electrical resistance varies linearly with temperature. The $\mathrm{Ni}$ foils only adds $0.5 \%$ weight and $0.04 \%$ cost to a conventional LiB single cell. They were able demonstrate fast charging without Li plating at temperatures as low as $-50^{\circ} \mathrm{C}$ with the help of the self-heating element.

Various techniques have been applied to detect anode Li plating. Among these, physical characterizations such as Conduction EPR, neutron diffraction and mass spectrometric titration are promising for understanding the mechanisms of Li plating, while electrochemical methods such as coulombic efficiency, discharge voltage profiles, electrochemical impedance and cell thickness analysis are more applicable to practical LiBs

The following table provides the Li detection methods, their advantages and current challenges: 


\begin{tabular}{|c|c|}
\hline Methods and advantages & Challenges \\
\hline $\begin{array}{l}\text { Three-electrode diagnostics } \\
\text { Constructing a special cell with anode, } \\
\text { cathode and a reference electrode to } \\
\text { study the charging rate at which anode } \\
\text { potential reaches } 0 \mathrm{~V} \text { vs } \mathrm{Li} / \mathrm{Li}^{+} \text {. } \\
\text { Easier to implement and a common } \\
\text { tool. }\end{array}$ & $\begin{array}{l}\text { Temperature distribution differences between } \\
\text { small } 3 \text { electrode cell and multi stack EV } \\
\text { battery is not linear. } \\
\text { Cathode polarization can interfere with the } \\
\text { anode Li plating curve. }\end{array}$ \\
\hline $\begin{array}{l}\text { Detection of voltage plateau }(\mathbf{d V} / \mathbf{d t}) \\
\text { The mixed potential associated with } \\
\text { simultaneous Li stripping and } \mathrm{Li}^{+} \\
\text {intercalation leads to a voltage plateau } \\
\text { and can be identified in the plot of } \\
\mathrm{dV} / \mathrm{dt} \text { vs \%SOC. } \\
\text { The most common method that can be } \\
\text { studied on full cell as opposed to } \\
\text { constructing a special cell. }\end{array}$ & $\begin{array}{l}\text { Interferences from graphite staging with } \mathrm{Li} \\
\text { plating at low charge rates. }\end{array}$ \\
\hline $\begin{array}{l}\text { Measurement of coulombic } \\
\text { efficiency (CE) } \\
\text { When Li plating happens, coulombic } \\
\text { efficiency decreases. } \\
\text { Easier to implement on the cell level. }\end{array}$ & $\begin{array}{l}\text { High precision coulometer and temperature } \\
\text { chamber are needed for accurate diagnosis. }\end{array}$ \\
\hline $\begin{array}{l}\text { Measurement of cell thickness } \\
\text { 1Ah of plated Li causes a volume } \\
\text { change of } 0.49 \mathrm{~cm}^{3} \text {, compared to } 0.12 \\
\mathrm{~cm}^{3} \text { for intercalated Li. Thickness } \\
\text { changes from Li deposition reflect on } \\
\text { cell thickness. } \\
\text { Easier to implement on cell level. }\end{array}$ & $\begin{array}{l}\text { SEI decomposition reactions in the cell can } \\
\text { lead to gassing which can affect the } \\
\text { measurement accuracy. It is also influenced } \\
\text { by the thickness measurement jig and } \\
\text { measurement point. }\end{array}$ \\
\hline $\begin{array}{l}\text { Cell Impedance Analysis } \\
\text { Charge transfer region of cell EIS } \\
\text { changes with SOC. Li plating changes } \\
\text { the trend from a good cell vs plated } \\
\text { cell. } \\
\text { Study can be performed on full cell. }\end{array}$ & $\begin{array}{l}\text { It requires step charging protocol like HPPC } \\
\text { with rest period included during which cell } \\
\text { impedance measurement is performed. }\end{array}$ \\
\hline $\begin{array}{l}\text { Accelerated Rate Calorimetry } \\
\text { (ARC) } \\
\text { Li plating is associated with thermal } \\
\text { signature which can be measured by } \\
\text { ARC. } \\
\text { It can be performed on full cell. }\end{array}$ & $\begin{array}{l}\text { Early exothermic reactions in ARC tests } \\
\text { needs massive Li plating. } \\
\text { ARC chamber must be custom made to test } \\
\text { the large EV batteries. }\end{array}$ \\
\hline $\begin{array}{l}\text { Optical Detection } \\
\text { SEM/TEM/Raman/XPS } \\
\text { Plated cell is teared down and anode } \\
\text { was analyzed by the above techniques } \\
\text { for Li plating. }\end{array}$ & $\begin{array}{l}\text { It is generally conducted ex situ. In the time } \\
\text { lapse between opening the cell and inspection, } \\
\text { some plated Li can intercalate back to } \\
\text { graphite. It is influenced by transfer time and } \\
\text { handling. }\end{array}$ \\
\hline
\end{tabular}




\begin{tabular}{|c|c|}
\hline & $\begin{array}{l}\text { Even if it is performed in situ, it can only } \\
\text { detect on a small section (localized). It is not } \\
\text { a cell level detection. }\end{array}$ \\
\hline $\begin{array}{l}\text { Li Nuclear magnetic resonance } \\
\text { (NMR) } \\
\text { The chemical shift of Li metal in NMR } \\
\text { spectra (245-270 ppm, depending on } \\
\text { Li metal structure). } \\
\text { The peak intensity in NMR spectra is } \\
\text { proportional to Li amount and is used } \\
\text { to quantify Li plating. }\end{array}$ & $\begin{array}{l}\text { As in the case with optical detection methods, } \\
\text { NMR gives direct evidence only microscopic } \\
\text { and electrode level Li plating. } \\
\text { It is not a cell level analysis. }\end{array}$ \\
\hline $\begin{array}{l}\text { Electron paramagnetic resonance } \\
\text { (EPR) } \\
\text { The EPR signal of } \mathrm{Li} \text { metal is much } \\
\text { narrower and its signal center is } \\
\text { slightly upfield compared with the } \\
\text { signal from the intercalated } \mathrm{Li}\left(\mathrm{Li}_{\mathrm{x}} \mathrm{C}_{6}\right) \text {. } \\
\text { The magnitude of EPR signal is related } \\
\text { to Li metal amount. } \\
\text { It is more sensitive than NMR. }\end{array}$ & It is in the early stage of development. \\
\hline $\begin{array}{l}\text { X- ray and Neutron Computer } \\
\text { Tomography } \\
\text { X-ray CT allowed for the } \\
\text { quantification of mechanical } \\
\text { degradation whereas Neutron } \\
\text { diffraction can identify Li-ion } \\
\text { transport and intercalation, electrolyte } \\
\text { wetting of the cell. }\end{array}$ & $\begin{array}{l}\text { It has the potential for real time battery } \\
\text { internal component imaging combined with } \\
\text { surface characterization. } \\
\text { It is in the early stage of implementation. }\end{array}$ \\
\hline $\begin{array}{l}\text { Acoustic detection } \\
\text { The transmitted ultrasonic signals shift } \\
\text { due to variations of the electrode } \\
\text { density and bulk modulus. } \\
\text { Can be studied on full cell. Easy to } \\
\text { implement. }\end{array}$ & $\begin{array}{l}\text { It is a bulk technique that can be performed } \\
\text { on a full cell. } \\
\text { It can identify Li plating but cannot identify } \\
\text { the location of Li plating initiation. It can be } \\
\text { combined with other optical detection } \\
\text { methods to get both cell level and } \\
\text { microscopic information. }\end{array}$ \\
\hline $\begin{array}{l}\text { Mass spectrometric titration } \\
\text { Titration of anode and estimation of } \\
\text { off gasses by mass spectrometry. } \\
\text { It can identify the difference between } \\
\text { inactive } \mathrm{Li} \text { and the SEI components on } \\
\text { plated Li down to } 20 \mathrm{nmol} \\
\text { concentration. }\end{array}$ & $\begin{array}{l}\text { It is a quantitative technique. } \\
\text { It is a component level analysis and is also an } \\
\text { ex situ technique. Therefore, it has the same } \\
\text { challenges as those of other ex-situ } \\
\text { techniques. }\end{array}$ \\
\hline
\end{tabular}




\section{Acknowledgments}

The authors appreciate the discussions and feedback from Dr. Dan Steingart of Columbia University and Dr. Bryan D. McCloskey of University of California, Berkeley.

\section{References}

1. C.-Y. Wang, G. Zhang, S. Ge, T. Xu, Y. Ji, X.-G. Yang and Y. Leng, Nature, 529, 515 (2016).

2. V. Etacheri, R. Marom, R. Elazari, G. Salitra and D. Aurbach, Energy \& Environmental Science, 4, 3243 (2011).

3. H. Jiang, Z. Lu, M. Wu, F. Ciucci and T. Zhao, Nano Energy, 23, 97 (2016).

4. C. R. Birkl, M. R. Roberts, E. McTurk, P. G. Bruce and D. A. Howey, J Power Sources, 341, 373 (2017).

5. M. Dubarry, G. Baure and A. Devie, J Electrochem Soc, 165, A773 (2018).

6. $\quad$ R. Xiong, Y. Duan, J. Cao and Q. Yu, Appl Energ, 217, 153 (2018).

7. S. J. Harris, E. K. Rahani and V. B. Shenoy, J Electrochem Soc, 159, A1501 (2012).

8. S. J. Harris, A. Timmons, D. R. Baker and C. Monroe, Chemical Physics Letters, 485, 265 (2010).

9. $\quad$ M. Smart and B. Ratnakumar, J Electrochem Soc, 158, A379 (2011).

10. A. N. Jansen, D. W. Dees, D. P. Abraham, K. Amine and G. L. Henriksen, J Power Sources, 174, 373 (2007).

11. J. Fan and S. Tan, J Electrochem Soc, 153, A1081 (2006).

12. C. K. Huang, J. Sakamoto, J. Wolfenstine and S. Surampudi, J Electrochem Soc, 147, 2893 (2000).

13. P. Arora, R. E. White and M. Doyle, J Electrochem Soc, 145, 3647 (1998).

14. M. Smart, B. Ratnakumar, L. Whitcanack, K. Chin, M. Rodriguez and S. Surampudi, IEEE aerospace and electronic systems magazine, 17, 16 (2002).

15. M. Smart and B. Ratnakumar, ECS Trans, 25, 241 (2010).

16. M. Smart, B. Ratnakumar, S. Surampudi, Y. Wang, X. Zhang, S. Greenbaum, A. Hightower, C. Ahn and B. Fultz, J Electrochem Soc, 146, 3963 (1999).

17. M. Zier, F. Scheiba, S. Oswald, J. Thomas, D. Goers, T. Scherer, M. Klose, H. Ehrenberg and J. Eckert, J Power Sources, 266, 198 (2014).

18. W. Lu, C. M. López, N. Liu, J. T. Vaughey and A. Jansen, J Electrochem Soc, 159, A566 (2012).

19. H.-P. Lin, D. Chua, M. Salomon, H. Shiao, M. Hendrickson, E. Plichta and S. Slane, Electrochem Solid St, 4, A71 (2001).

20. A. Whitehead, M. Perkins and J. Owen, J Electrochem Soc, 144, L92 (1997).

21. M. Petzl and M. A. Danzer, J Power Sources, 254, 80 (2014).

22. C. Uhlmann, J. Illig, M. Ender, R. Schuster and E. Ivers-Tiffée, J Power Sources, 279, 428 (2015).

23. S. Schindler, M. Bauer, M. Petzl and M. A. Danzer, J Power Sources, 304, 170 (2016).

24. S. Solchenbach, D. Pritzl, E. J. Y. Kong, J. Landesfeind and H. A. Gasteiger, J Electrochem Soc, 163, A2265 (2016).

25. Y. Zhang and C.-Y. Wang, J Electrochem Soc, 156, A527 (2009). 
26. Y. Leng, S. Ge, D. Marple, X.-G. Yang, C. Bauer, P. Lamp and C.-Y. Wang, $J$ Electrochem Soc, 164, A1037 (2017).

27. S. J. An, J. Li, C. Daniel, S. Kalnaus and D. L. Wood III, J Electrochem Soc, 164, A1755 (2017).

28. N. Ghanbari, T. Waldmann, M. Kasper, P. Axmann and M. Wohlfahrt-Mehrens, Ecs Electrochem Lett, 4, A100 (2015).

29. Y. Krämer, C. Birkenmaier, J. Feinauer, A. Hintennach, C. L. Bender, M. Meiler, V. Schmidt, R. E. Dinnebier and T. Schleid, Chemistry-A European Journal, 21, 6062 (2015).

30. J. Wandt, C. Marino, H. A. Gasteiger, P. Jakes, R.-A. Eichel and J. Granwehr, Energy \& environmental science, 8, 1358 (2015).

31. J. Wandt, P. Jakes, J. Granwehr, R.-A. Eichel and H. A. Gasteiger, Materials Today, 21, 231 (2018).

32. J. Arai, Y. Okada, T. Sugiyama, M. Izuka, K. Gotoh and K. Takeda, J Electrochem Soc, 162, A952 (2015).

33. H. Ge, T. Aoki, N. Ikeda, S. Suga, T. Isobe, Z. Li, Y. Tabuchi and J. Zhang, $J$ Electrochem Soc, 164, A1050 (2017).

34. J. Burns, D. Stevens and J. Dahn, J Electrochem Soc, 162, A959 (2015).

35. Q. Liu, R. Petibon, C. Du and J. Dahn, J Electrochem Soc, 164, A1173 (2017).

36. B. Bitzer and A. Gruhle, J Power Sources, 262, 297 (2014).

37. B. Rieger, S. F. Schuster, S. V. Erhard, P. J. Osswald, A. Rheinfeld, C. Willmann and A. Jossen, Journal of Energy Storage, 8, 1 (2016).

38. C. Birkenmaier, B. Bitzer, M. Harzheim, A. Hintennach and T. Schleid, $J$ Electrochem Soc, 162, A2646 (2015).

39. F. Grimsmann, T. Gerbert, F. Brauchle, A. Gruhle, J. Parisi and M. Knipper, $J$ Power Sources, 365, 12 (2017).

40. V. Zinth, C. von Lüders, M. Hofmann, J. Hattendorff, I. Buchberger, S. Erhard, J. Rebelo-Kornmeier, A. Jossen and R. Gilles, J Power Sources, 271, 152 (2014).

41. R. V. Bugga and M. C. Smart, Ecs Transactions, 25, 241 (2010).

42. M. Bauer, B. Rieger, S. Schindler, P. Keil, M. Wachtler, M. A. Danzer and A. Jossen, Journal of Energy Storage, 10, 1 (2017).

43. C. von Lüders, V. Zinth, S. V. Erhard, P. J. Osswald, M. Hofmann, R. Gilles and A. Jossen, J Power Sources, 342, 17 (2017).

44. T. Waldmann and M. Wohlfahrt-Mehrens, Electrochim Acta, 230, 454 (2017).

45. U. R. Koleti, T. Q. Dinh and J. Marco, J Power Sources, 451, 227798 (2020).

46. R. Carter, E. J. Klein, T. A. Kingston and C. T. Love, Frontiers in Energy Research, 7, 144 (2019).

47. M. T. Pham, J. J. Darst, D. P. Finegan, J. B. Robinson, T. M. Heenan, M. D. Kok, F. Iacoviello, R. Owen, W. Q. Walker and O. V. Magdysyuk, J Power Sources, 228039 (2020).

48. E. J. McShane, A. M. Colclasure, D. E. Brown, Z. M. Konz, K. Smith and B. D. McCloskey, ACS Energy Letters (2020).

49. W. Fang, O. J. Kwon and C. Y. Wang, International journal of energy research, 34, 107 (2010).

50. Y. Ji, Y. Zhang and C.-Y. Wang, J Electrochem Soc, 160, A636 (2013).

51. X.-G. Yang, C. Bauer and C.-Y. Wang, J Power Sources, 327, 414 (2016).

52. X.-G. Yang, G. Zhang and C.-Y. Wang, J Power Sources, 328, 203 (2016).

53. X.-G. Yang, T. Liu and C.-Y. Wang, J Power Sources, 342, 598 (2017). 
54. L. Liu, J. Park, X. Lin, A. M. Sastry and W. Lu, J Power Sources, 268, 482 (2014).

55. L. Liu, P. Guan and C. Liu, J Electrochem Soc, 164, A3163 (2017).

56. B. Wu and W. Lu, J Power Sources, 360, 360 (2017).

57. $\quad$ P. Arora, M. Doyle and R. E. White, J Electrochem Soc, 146, 3543 (1999).

58. R. D. Perkins, A. V. Randall, X. Zhang and G. L. Plett, J Power Sources, 209, 318 (2012).

59. N. Legrand, B. Knosp, P. Desprez, F. Lapicque and S. Raël, J Power Sources, 245, 208 (2014).

60. X.-G. Yang, Y. Leng, G. Zhang, S. Ge and C.-Y. Wang, J Power Sources, 360, 28 (2017).

61. T. Danner, M. Singh, S. Hein, J. Kaiser, H. Hahn and A. Latz, J Power Sources, 334, 191 (2016).

62. S. Hein and A. Latz, Electrochim Acta, 201, 354 (2016).

63. M. A. Cabañero, J. Altmann, L. Gold, N. Boaretto, J. Müller, S. Hein, J. Zausch, J. Kallo and A. Latz, Energy, 171, 1217 (2019).

64. J. Feinauer, S. Hein, S. Rave, S. Schmidt, D. Westhoff, J. Zausch, O. Iliev, A. Latz, M. Ohlberger and V. Schmidt, Journal of Computational Science, 31, 172 (2019).

65. T. Waldmann, M. Wilka, M. Kasper, M. Fleischhammer and M. WohlfahrtMehrens, J Power Sources, 262, 129 (2014).

66. J. Remmlinger, S. Tippmann, M. Buchholz and K. Dietmayer, J Power Sources, 254, 268 (2014).

67. M. Petzl, M. Kasper and M. A. Danzer, J Power Sources, 275, 799 (2015).

68. $\quad$ S. S. Zhang, K. Xu and T. Jow, J Power Sources, 160, 1349 (2006).

69. M. Ouyang, Z. Chu, L. Lu, J. Li, X. Han, X. Feng and G. Liu, J Power Sources, 286, 309 (2015).

70. R. C. Bhardwaj, T. Hwang and R. M. Mank, Modulated, temperature-based multiCC-CV charging technique for Li-ion/Li-polymer batteries, in, Google Patents (2014).

71. Y. Itou and Y. Ukyo, J Power Sources, 146, 39 (2005).

72. M. W. Verbrugge and B. J. Koch, J Electrochem Soc, 150, A374 (2003).

73. T. Waldmann, M. Kasper and M. Wohlfahrt-Mehrens, Electrochim Acta, 178, 525 (2015).

74. T. R. Garrick, J. Gao, X. Yang and B. Koch, Submitted to J. Electrochem. Soc. (2020).

75. J.-i. Yamaki, S.-i. Tobishima, K. Hayashi, K. Saito, Y. Nemoto and M. Arakawa, J Power Sources, 74, 219 (1998).

76. P. J. Mohr, B. N. Taylor and D. B. Newell, Journal of Physical and Chemical Reference Data, 80, 633 (2008).

77. S. Ahmed, I. Bloom, A. N. Jansen, T. Tanim, E. J. Dufek, A. Pesaran, A. Burnham, R. B. Carlson, F. Dias and K. Hardy, J Power Sources, 367, 250 (2017).

78. A. Smith, J. Burns and J. Dahn, Electrochem Solid St, 13, A177 (2010).

79. J. Burns, N. Sinha, G. Jain, H. Ye, C. M. VanElzen, W. Lamanna, A. Xiao, E. Scott, J. Choi and J. Dahn, J Electrochem Soc, 159, A1105 (2012).

80. $\quad$ K. Zachary M., M. Eric J. and M. Bryan D., Voltage Relaxation to Detect the Onset of Lithium Plating on Graphite for Fast Charging (2020).

81. I. D. Campbell, M. Marzook, M. Marinescu and G. J. Offer, J Electrochem Soc, 166, A725 (2019).

82. K. A. Smith, IEEE Control Systems Magazine, 30, 18 (2010).

83. A. Seaman, T.-S. Dao and J. McPhee, J Power Sources, 256, 410 (2014). 
84. M. Doyle, T. F. Fuller and J. Newman, J Electrochem Soc, 140, 1526 (1993).

85. K. E. Thomas, J. Newman and R. M. Darling, in Advances in lithium-ion batteries, p. 345 , Springer (2002).

86. K. E. Thomas and J. Newman, J Electrochem Soc, 150, A176 (2003).

87. J. S. Newman and C. W. Tobias, J Electrochem Soc, 109, 1183 (1962).

88. J. Newman and W. Tiedemann, AIChE Journal, 21, 25 (1975).

89. J. Newman and K. E. Thomas-Alyea, Electrochemical systems, John Wiley \& Sons (2012).

90. J. S. Dunning, D. N. Bennion and J. Newman, J Electrochem Soc, 120, 906 (1973).

91. J. S. Dunning, D. N. Bennion and J. Newman, J Electrochem Soc, 118, 1251 (1971).

92. M. Tang, P. Albertus and J. Newman, J Electrochem Soc, 156, A390 (2009).

93. D. Ren, K. Smith, D. Guo, X. Han, X. Feng, L. Lu, M. Ouyang and J. Li, J Electrochem Soc, 165, A2167 (2018).

94. X. M. Liu, A. Fang, M. P. Haataja and C. B. Arnold, J Electrochem Soc, 165, A1147 (2018).

95. S. Szabó, International Reviews in Physical Chemistry, 10, 207 (1991).

96. K. Yan, Z. Lu, H.-W. Lee, F. Xiong, P.-C. Hsu, Y. Li, J. Zhao, S. Chu and Y. Cui, Nature Energy, 1, 1 (2016).

97. I. Morcos, Journal of Electroanalytical Chemistry and Interfacial Electrochemistry, 66, 250 (1975).

98. T. Tran and K. Kinoshita, Journal of Electroanalytical Chemistry, 386, 221 (1995).

99. L. Gasparotto, N. Borisenko, N. Bocchi, S. Z. El Abedin and F. Endres, Physical Chemistry Chemical Physics, 11, 11140 (2009).

100. C. A. Paddon and R. G. Compton, The Journal of Physical Chemistry C, 111, 9016 (2007).

101. Y. Mo, Y. Gofer, E. Hwang, Z. Wang and D. A. Scherson, Journal of Electroanalytical Chemistry, 409, 87 (1996).

102. M. L. Urquiza, M. Otero, G. L. Luque, D. Barraco and E. P. Leiva, Electrochim Acta, 208, 92 (2016).

103. M. K. Datta, B. Gattu, R. Kuruba, P. M. Shanthi and P. N. Kumta, J Power Sources, 467, 228243 (2020).

104. M. Verbrugge, D. Baker and X. Xiao, J Electrochem Soc, 163, A262 (2016).

105. M. Verbrugge, D. Baker, B. Koch, X. Xiao and W. Gu, J Electrochem Soc, 164, E3243 (2017).

106. D. R. Baker and M. W. Verbrugge, J Electrochem Soc, 165, A3952 (2018).

107. D. R. Baker, M. W. Verbrugge and W. Gu, J Electrochem Soc, 166, A521 (2019).

108. D. R. Baker and M. W. Verbrugge, J Electrochem Soc, 167, 013504 (2019).

109. H. Zhang and M.-Y. Chow, in iEEE PES General Meeting, p. 1 (2010).

110. S. Abu-Sharkh and D. Doerffel, J Power Sources, 130, 266 (2004).

111. R. C. Kroeze and P. T. Krein, in 2008 IEEE Power Electronics Specialists Conference, p. 1336 (2008).

112. M. Chen and G. A. Rincon-Mora, IEEE transactions on energy conversion, 21, 504 (2006).

113. L. Gao, S. Liu and R. A. Dougal, IEEE transactions on components and packaging technologies, 25, 495 (2002).

114. F. Baronti, G. Fantechi, E. Leonardi, R. Roncella and R. Saletti, in IECON 201036th Annual Conference on IEEE Industrial Electronics Society, p. 2329 (2010). 
115. O. Erdinc, B. Vural and M. Uzunoglu, in 2009 International Conference on Clean Electrical Power, p. 383 (2009).

116. Y. Hu, S. Yurkovich, Y. Guezennec and B. Yurkovich, Control Engineering Practice, 17, 1190 (2009).

117. Y. Hu, S. Yurkovich, Y. Guezennec and B. Yurkovich, J Power Sources, 196, 449 (2011).

118. L. Lam, P. Bauer and E. Kelder, in 2011 IEEE 33rd International Telecommunications Energy Conference (INTELEC), p. 1 (2011).

119. J. Zhang, S. Ci, H. Sharif and M. Alahmad, in 2010 Twenty-Fifth Annual IEEE Applied Power Electronics Conference and Exposition (APEC), p. 672 (2010).

120. B. Schweighofer, K. M. Raab and G. Brasseur, IEEE transactions on instrumentation and measurement, 52, 1087 (2003).

121. H. Chan, in 2000 IEEE Power Engineering Society Winter Meeting. Conference Proceedings (Cat. No. O0CH37077), p. 470 (2000).

122. T. Kim and W. Qiao, IEEE Transactions on Energy Conversion, 26, 1172 (2011).

123. T. Hu, B. Zanchi and J. Zhao, IEEE Transactions on Energy Conversion, 26, 787 (2011).

124. E. Kuhn, C. Forgez, P. Lagonotte and G. Friedrich, J Power Sources, 158, 1490 (2006).

125. E. Karden, S. Buller and R. W. De Doncker, J Power Sources, 85, 72 (2000).

126. S. Buller, M. Thele, R. W. De Doncker and E. Karden, IEEE Transactions on Industry Applications, 41, 742 (2005).

127. S. Buller, M. Thele, E. Karden and R. W. De Doncker, J Power Sources, 113, 422 (2003).

128. V. R. Subramanian, V. Boovaragavan and V. D. Diwakar, Electrochem Solid St, 10, A255 (2007).

129. V. R. Subramanian, V. Boovaragavan, V. Ramadesigan and M. Arabandi, J Electrochem Soc, 156, A260 (2009).

130. V. Ramadesigan, V. Boovaragavan, J. C. Pirkle Jr and V. R. Subramanian, J Electrochem Soc, 157, A854 (2010).

131. P. W. Northrop, V. Ramadesigan, S. De and V. R. Subramanian, J Electrochem Soc, 158, A1461 (2011).

132. V. Ramadesigan, K. Chen, N. A. Burns, V. Boovaragavan, R. D. Braatz and V. R. Subramanian, J Electrochem Soc, 158, A1048 (2011).

133. L. Cai and R. E. White, J Electrochem Soc, 156, A154 (2008).

134. M. Guo and R. E. White, J Power Sources, 198, 322 (2012).

135. B. Ng, P. T. Coman, W. E. Mustain and R. E. White, J Power Sources, 445, 227296 (2020).

136. Y. Dai, L. Cai and R. E. White, J Electrochem Soc, 160, A182 (2012).

137. Y. Dai, L. Cai and R. E. White, J Electrochem Soc, 161, E3348 (2014).

138. X. Jin, A. Vora, V. Hoshing, T. Saha, G. Shaver, R. E. García, O. Wasynczuk and S. Varigonda, J Power Sources, 342, 750 (2017).

139. Z. Chu, G. L. Plett, M. S. Trimboli and M. Ouyang, Journal of Energy Storage, 25, 100828 (2019).

140. Y. Yin, Y. Hu, S.-Y. Choe, H. Cho and W. T. Joe, J Power Sources, 423, 367 (2019).

141. L. Xia, E. Najafi, Z. Li, H. Bergveld and M. Donkers, Appl Energ, 208, 1285 (2017).

142. M. Farag, M. Fleckenstein and S. Habibi, J Power Sources, 342, 351 (2017). 
143. X.-B. Meng, H.-X. Li and H.-D. Yang, IEEE Transactions on Industrial Informatics, 15, 2838 (2018).

144. A. Rodríguez, G. L. Plett and M. S. Trimboli, eTransportation, 1, 100009 (2019).

145. A. Farmann and D. U. Sauer, Appl Energ, 225, 1102 (2018).

146. A. B. Ansari, V. Esfahanian and F. Torabi, Modares Mechanical Engineering, 15, 43 (2016).

147. Z. Li, D. Danilov, M. Donkers and H. J. Bergveld, in Proc. 35th Benelux Meeting Syst. Control, p. 43 (2016).

148. S. Yuan, L. Jiang, C. Yin, H. Wu and X. Zhang, J Power Sources, 352, 245 (2017).

149. A. Subramaniam, S. Kolluri, C. D. Parke, M. Pathak, S. Santhanagopalan and V. R. Subramanian, J Electrochem Soc, 167, 013534 (2019).

150. X. Zhao, Y. Yin, Y. Hu and S.-Y. Choe, J Power Sources, 418, 61 (2019).

151. X. Zhao, Y. Bi and S.-Y. Choe, SAE International Journal of Alternative Powertrains, 6 (2017).

152. X. Zhao, Y. Bi, S.-Y. Choe and S.-Y. Kim, Electrochim Acta, 280, 41 (2018).

153. X. Li, M. Xiao and S.-Y. Choe, Electrochim Acta, 97, 66 (2013).

154. B. Ng, P. T. Coman, E. Faegh, X. Peng, S. G. Karakalos, X. Jin, W. E. Mustain and R. E. White, ACS Applied Energy Materials, 3, 3653 (2020).

155. U. R. Koleti, C. Zhang, R. Malik, T. Q. Dinh and J. Marco, Journal of Energy Storage, 24, 100798 (2019).

156. S. P. Rangarajan, Y. Barsukov and P. P. Mukherjee, Journal of Materials Chemistry A, 8, 13077 (2020).

157. X. Wu, W. Wang and J. Du, International Journal of Energy Research, 44, 1775 (2020).

158. M. Ecker, P. S. Sabet and D. U. Sauer, Appl Energ, 206, 934 (2017).

159. X. Li, S.-Y. Choe and W. T. Joe, J Power Sources, 294, 545 (2015).

160. Y. Zhao, S.-Y. Choe and J. Kee, Electrochim Acta, 270, 440 (2018).

161. Y. Bi, X. Zhao and S.-Y. Choe, in 2019 American Control Conference (ACC), p. 3155 (2019).

162. M. Song and S.-Y. Choe, J Power Sources, 436, 226835 (2019).

163. Y. Yin and S.-Y. Choe, Appl Energ, 271, 115232 (2020).

164. G. H. Florentino, Model Predictive Control Implementations for Management of Lithium-ion Battery Cells and Packs Using Reduced-order Electrochemical Models, in, University of Colorado Colorado Springs. Kraemer Family Library (2018).

165. V. Ramadesigan, P. W. Northrop, S. De, S. Santhanagopalan, R. D. Braatz and V. R. Subramanian, J Electrochem Soc, 159, R31 (2012).

166. V. R. Subramanian, V. D. Diwakar and D. Tapriyal, J Electrochem Soc, 152, A2002 (2005).

167. G. G. Botte, V. R. Subramanian and R. E. White, Electrochim Acta, 45, 2595 (2000).

168. M. T. Lawder, B. Suthar, P. W. Northrop, S. De, C. M. Hoff, O. Leitermann, M. L. Crow, S. Santhanagopalan and V. R. Subramanian, Proceedings of the IEEE, 102, 1014 (2014).

169. V. Ramadesigan, V. Boovaragavan, M. Arabandi, K. Chen, H. Tsukamoto, R. Braatz and V. Subramanian, Ecs Transactions, 19, 11 (2009).

170. Y. Cao, S. B. Lee, V. R. Subramanian and V. M. Zavala, Journal of Process Control, 90, 46 (2020).

171. S. Kolluri, S. V. Aduru, M. Pathak, R. D. Braatz and V. R. Subramanian, $J$ Electrochem Soc, 167, 063505 (2020). 
172. S. Alavi, C. Birkl and D. Howey, J Power Sources, 288, 345 (2015).

173. S. Dey and B. Ayalew, Journal of Dynamic Systems, Measurement, and Control, 139 (2017).

174. G. K. Singh, G. Ceder and M. Z. Bazant, Electrochim Acta, 53, 7599 (2008).

175. W. Waag, S. Käbitz and D. U. Sauer, Appl Energ, 102, 885 (2013).

176. M. Singh, J. Kaiser and H. Hahn, Batteries, 2 , 35 (2016).

177. J. Schmalstieg, S. Käbitz, M. Ecker and D. U. Sauer, J Power Sources, 257, 325 (2014).

178. M. B. Pinson and M. Z. Bazant, J Electrochem Soc, 160, A243 (2012).

179. M.-T. von Srbik, M. Marinescu, R. F. Martinez-Botas and G. J. Offer, J Power Sources, 325, 171 (2016).

180. H. Lundgren, P. Svens, H. Ekström, C. Tengstedt, J. Lindström, M. Behm and G. Lindbergh, J Electrochem Soc, 163, A309 (2015).

181. T. Waldmann, B.-I. Hogg, M. Kasper, S. Grolleau, C. G. Couceiro, K. Trad, B. P. Matadi and M. Wohlfahrt-Mehrens, J Electrochem Soc, 163, A1232 (2016).

182. M. Mathew, S. Janhunen, M. Rashid, F. Long and M. Fowler, Energies, 11, 1490 (2018).

183. K. S. Hariharan and V. S. Kumar, J Power Sources, 222, 210 (2013).

184. S. Cho, H. Jeong, C. Han, S. Jin, J. H. Lim and J. Oh, Computers \& Chemical Engineering, 41, 1 (2012).

185. Y. Qi and S. J. Harris, J Electrochem Soc, 157, A741 (2010).

186. S.-C. Yin, Y.-H. Rho, I. Swainson and L. Nazar, Chem Mater, 18, 1901 (2006).

187. J. Shu, J Solid State Electr, 13, 1535 (2009).

188. F. Sagane, R. Shimokawa, H. Sano, H. Sakaebe and Y. Iriyama, J Power Sources, 225, 245 (2013).

189. L. Gireaud, S. Grugeon, S. Laruelle, B. Yrieix and J.-M. Tarascon, Electrochem Commun, 8, 1639 (2006).

190. J. Steiger, D. Kramer and R. Mönig, Electrochim Acta, 136, 529 (2014).

191. J. Guo, Z. Wen, M. Wu, J. Jin and Y. Liu, Electrochem Commun, 51, 59 (2015).

192. K. J. Harry, D. T. Hallinan, D. Y. Parkinson, A. A. MacDowell and N. P. Balsara, Nature materials, 13, 69 (2014).

193. A. Yermukhambetova, C. Tan, S. R. Daemi, Z. Bakenov, J. A. Darr, D. J. Brett and P. R. Shearing, Scientific reports, 6, 35291 (2016).

194. F. Sun, L. Zielke, H. Markötter, A. Hilger, D. Zhou, R. Moroni, R. Zengerle, S. Thiele, J. Banhart and I. Manke, ACS nano, 10, 7990 (2016).

195. D. Zhang, A. Forner-Cuenca, O. O. Taiwo, V. Yufit, F. R. Brushett, N. P. Brandon, S. Gu and Q. Cai, J Power Sources, 447, 227249 (2020).

196. R. F. Ziesche, T. Arlt, D. P. Finegan, T. M. Heenan, A. Tengattini, D. Baum, N. Kardjilov, H. Markötter, I. Manke and W. Kockelmann, Nat Commun, 11, 1 (2020).

197. B. Key, R. Bhattacharyya, M. Morcrette, V. Seznec, J.-M. Tarascon and C. P. Grey, Journal of the American Chemical Society, 131, 9239 (2009).

198. F. Chevallier, M. Letellier, M. Morcrette, J.-M. Tarascon, E. Frackowiak, J.-N. Rouzaud and F. Béguin, Electrochem Solid St, 6, A225 (2003).

199. M. Letellier, F. Chevallier and M. Morcrette, Carbon, 45, 1025 (2007).

200. R. Gerald Ii, C. Johnson, J. Rathke, R. Klingler, G. Sandí and L. Scanlon, J Power Sources, 89, 237 (2000).

201. Y.-C. Hsieh, M. Leißing, S. Nowak, B.-J. Hwang, M. Winter and G. Brunklaus, Cell Reports Physical Science, 100139 (2020). 
202. M. Leskes, G. Kim, T. Liu, A. L. Michan, F. Aussenac, P. Dorffer, S. Paul and C. P. Grey, The Journal of Physical Chemistry Letters, 8, 1078 (2017).

203. Y. Jin, N.-J. H. Kneusels, P. C. Magusin, G. Kim, E. Castillo-Martínez, L. E. Marbella, R. N. Kerber, D. J. Howe, S. Paul and T. Liu, Journal of the American Chemical Society, 139, 14992 (2017).

204. Y. Jin, N.-J. H. Kneusels, L. E. Marbella, E. Castillo-Martínez, P. C. Magusin, R. S. Weatherup, E. Jónsson, T. Liu, S. Paul and C. P. Grey, Journal of the American Chemical Society, 140, 9854 (2018).

205. M. A. Hope, B. L. Rinkel, A. B. Gunnarsdóttir, K. Märker, S. Menkin, S. Paul, I. V. Sergeyev and C. P. Grey, Nat Commun, 11, 1 (2020).

206. F. Rosciano, M. Holzapfel, W. Scheifele and P. Novák, Journal of Applied Crystallography, 41, 690 (2008).

207. M. Roberts, J. J. Biendicho, S. Hull, P. Beran, T. Gustafsson, G. Svensson and K. Edström, J Power Sources, 226, 249 (2013).

208. T. Kulova, A. Skundin, E. Nizhnikovskii and A. Fesenko, Russian Journal of Electrochemistry, 42, 259 (2006).

209. G. Feher and A. Kip, Physical Review, 98, 337 (1955).

210. J. H. Pifer and R. Magno, Physical Review B, 3, 663 (1971).

211. M. Sathiya, J.-B. Leriche, E. Salager, D. Gourier, J.-M. Tarascon and H. Vezin, Nat Commun, 6, 1 (2015).

212. A. Niemöller, P. Jakes, R.-A. Eichel and J. Granwehr, Scientific reports, 8, 1 (2018).

213. F. J. Dyson, Physical Review, 98, 349 (1955).

214. P. Glover and P. Mansfield, Reports on progress in physics, 65, 1489 (2002).

215. M. Weiger, D. Schmidig, S. Denoth, C. Massin, F. Vincent, M. Schenkel and M.

Fey, Concepts in Magnetic Resonance Part B: Magnetic Resonance Engineering: An Educational Journal, 33, 84 (2008).

216. A. Webb, Concepts in Magnetic Resonance Part A: An Educational Journal, 22, 25 (2004).

217. G. Maresch, M. Mehring and S. Emid, Physica B+C, 138, 261 (1986).

218. M.-T. F. Rodrigues, G. Babu, H. Gullapalli, K. Kalaga, F. N. Sayed, K. Kato, J. Joyner and P. M. Ajayan, nature energy, 2, 1 (2017).

219. A. Mistry, C. Fear, R. Carter, C. T. Love and P. P. Mukherjee, ACS Energy Letters, 4, 156 (2018).

220. R. Carter, B. Huhman, C. T. Love and I. V. Zenyuk, J Power Sources, 381, 46 (2018).

221. F. B. Spingler, W. Wittmann, J. Sturm, B. Rieger and A. Jossen, J Power Sources, 393, 152 (2018).

222. Q. Liu, D. Xiong, R. Petibon, C. Du and J. Dahn, J Electrochem Soc, 163, A3010 (2016).

223. A. Hsieh, S. Bhadra, B. Hertzberg, P. Gjeltema, A. Goy, J. W. Fleischer and D. A. Steingart, Energy \& environmental science, 8, 1569 (2015).

224. G. Davies, K. W. Knehr, B. Van Tassell, T. Hodson, S. Biswas, A. G. Hsieh and D. A. Steingart, J Electrochem Soc, 164, A2746 (2017).

225. L. Gold, T. Bach, W. Virsik, A. Schmitt, J. Müller, T. E. Staab and G. Sextl, J Power Sources, 343, 536 (2017).

226. J. B. Robinson, M. Maier, G. Alster, T. Compton, D. J. Brett and P. R. Shearing, Physical Chemistry Chemical Physics, 21, 6354 (2019). 
227. Z. Deng, Z. Huang, Y. Shen, Y. Huang, H. Ding, A. Luscombe, M. Johnson and J. Dahn.

228. C. Bommier, W. Chang, Y. Lu, J. Yeung, G. Davies, R. Mohr, M. Williams and D. Steingart, Cell Reports Physical Science, 100035 (2020).

229. W. Chang, R. Mohr, A. Kim, A. Raj, G. Davies, K. Denner, J. H. Park and D. Steingart, Journal of Materials Chemistry A, 8, 16624 (2020).

230. S. E. Renfrew and B. D. McCloskey, Journal of the American Chemical Society, 139, 17853 (2017).

231. B. D. McCloskey, A. Valery, A. C. Luntz, S. R. Gowda, G. M. Wallraff, J. M. Garcia, T. Mori and L. E. Krupp, The journal of physical chemistry letters, 4, 2989 (2013). 232. S. E. Renfrew and B. D. McCloskey, ACS Applied Energy Materials, 2, 3762 (2019).

233. M. M. Ottakam Thotiyl, S. A. Freunberger, Z. Peng and P. G. Bruce, Journal of the American Chemical Society, 135, 494 (2013).

234. X.-G. Yang, G. Zhang, S. Ge and C.-Y. Wang, Proceedings of the National Academy of Sciences, 115, 7266 (2018). 